\title{
The Influence of Spiritual Traditions on the Interplay of Subjective and Normative Interpretations of Meaningful Work
}

\author{
Mai Chi Vu ${ }^{1}$ D $\cdot$ Nicholas Burton ${ }^{1}$ D
}

Received: 8 May 2020 / Accepted: 8 July 2021 / Published online: 4 August 2021

(c) The Author(s) 2021

\begin{abstract}
This paper argues that the principles of spiritual traditions provide normative 'standards of goodness' within which practitioners evaluate meaningful work. Our comparative study of practitioners in the Buddhist and Quaker traditions provide a fine-grained analysis to illuminate, that meaningfulness is deeply connected to particular tradition-specific philosophical and theological ideas. In the Buddhist tradition, meaningfulness is temporal and rooted in Buddhist principles of non-attachment, impermanence and depending-arising, whereas in the Quaker tradition, the Quaker testimonies and theological ideas frame meaningfulness as eternal. Surprisingly, we find that when faced with unethical choices and clashes between organizational normativity and spiritual normativity, Buddhist practitioners acknowledge the temporal character of meaningfulness and compromise their moral values, whereas in contrast, Quaker practitioners morally disengage from meaningless work. Our study highlights how normative commitments in different spiritual traditions can influence different levels of adaptability in finding work meaningful and stresses the central importance of normative commitments in meaningful work. Our study concludes with practical implications and future pathways for inter-disciplinary research.
\end{abstract}

Keywords Meaningful work $\cdot$ Spirituality $\cdot$ Buddhist $\cdot$ Quaker

\section{Introduction}

Meaningful work is an "essentially contested concept" (Gallie, 1956, quoted in Bailey et al., 2019a, p. 482), complex, and multi-dimensional (e.g., Ciulla, 2012; Lips-Wiersma et al., 2020; May et al., 2014; Michaelson, 2009, 2019; Wolf, 2010; Yeoman, 2014), without consensus on a universal or interdisciplinary definition (e.g., Bailey et al., 2019a; Lepisto \& Pratt, 2017). While meaningful work is typically defined as a subjective experience (e.g., see Bailey et al., 2019a for a review), there is also no universal agreement about the best way to evaluate subjective experience (BothNwabuwe et al., 2017). Meaningful work also comprises, however, objective features that are often dictated by societal and cultural contexts (e.g., Lepisto \& Pratt, 2017; Mitra \&

Mai Chi Vu

mai.c.vu@northumbria.ac.uk

Nicholas Burton

n.burton@northumbria.ac.uk

1 Newcastle Business School, Northumbria University, Sutherland Building, 2 Ellison Pl,

Newcastle upon Tyne NE1 8ST, UK
Buzzanell, 2017), different institutional logics (Reinecke, et al., 2017), as well as by organizations through job design (Bailey et al., 2019a, 2019b), human resource management and leadership that can either enable the goods of autonomy, freedom or recognition (Wolf, 2010; Yeoman, 2014) or prescribe a particular sense of meaning that creates tensions and moral dilemmas.

Within the field of business ethics, meaningful work is an important element of what constitutes a good life (Beadle $\&$ Knight, 2012). Business ethics scholars have focused on normative ethics to explain how organizations have a moral duty to provide, and individuals to engage in the pursuit of, meaningful work (Michaelson, et al., 2014, p. 81). For example, organizations can play a crucial role in promoting an ethical workplace through responsible and ethical leadership (e.g., Bailey \& Madden, 2016; Wang \& Xu, 2019) and to provide working conditions that can encourage employees to find meaningful work (Ciulla, 2012; Michaelson et al., 2014). While studies have indicated the importance of normativity in work (e.g., Lips-Wiersma \& Morris, 2009; Michaelson et al., 2014), when meaning becomes 'a form of normative control' (Lips-Wiersma \& Morris, 2009, p. 492), the possibility of an authentic sense of meaningful work is 
challenged. Thus, concerns have arisen as to who has the power to determine meaning at work (Harding, 2019) as prescribed organizational practices or cultures may clash with individuals' subjective interpretations of meaning (Carton, 2017).

In normative approaches to meaningful work, much of the literature has similarly focused on how the moral worth of work is both subjective, and yet at the same time objective in the sense that worth infers conformity to some external or universal standard of goodness (Ciulla, 2000; Michaelson et al., 2014). It is argued that solely subjective interpretations of meaningful work cannot adequately reflect a "standard of judgment" (Wolf, 2010, p. 43). Thus, there is a timely need to deepen existing understandings of the dynamic interplay between subjective-normative interpretations of meaningful work (Michaelson et al., 2014). The need for further research is no more pressing than in contexts characterized by significant differences in ethical and moral priorities (Michaelson et al., 2014, p. 85).

One important source of these kinds of difference lies in an individual's spirituality or religion. Studies often indicate that individuals locate their spirituality as a central feature of their pursuit to find meaning or purpose in life (LipsWiersma, 2002), and underpin their appetite to contribute to the greater good (Bailey et al., 2019a). Surprisingly, there have been few studies exploring meaningful work within the workplace spirituality literature (for a review, see Bailey et al., 2019b) and yet a deeper understanding of subjectivenormative interpretations of meaningful work from the perspective of different spiritual traditions can help unpack the underlying tensions associated with this dynamic. Despite an implied standard of goodness or virtue in the notion of a 'tradition' (Moore \& Beadle, 2006; Robson, 2015), we also know that the practices of different traditions are malleable to subjective interpretation. Further, given the variation in philosophical and normative commitments between different spiritual traditions, there are also unanswered questions about how meaningful work varies across philosophical and theological attitudes that can potentially enrich 'crosscultural dialogue' on meaningful work (Michaelson et al., 2014, p. 88).

Following, we unpack the interplay between the normative content of two spiritual traditions and the subjective interpretations of experienced practitioners. Our research questions explored the following issues: (1) How the subjective-normative interface of spirituality shapes and legitimizes what is considered meaningful work? (2) What tensions were experienced, and how were they overcome? We collected interview data from two cohorts of individuals who described themselves as either Buddhist or Quaker, and who held a leadership or managerial role in a profit or non-profit organization. Different traditions teach different philosophies of life (Huang \& Wang, 2019). We chose the Buddhist and Quaker contexts to help us illuminate how these differences impact upon subjective interpretations of meaningful work. While both traditions share epistemic standards relating to the primacy of personal experience, they also have important differences; none more so than the differences of belief in God. For example, Quakerism has Christian roots and a theology grounded in finding unity with God (Dandelion, 2008). In contrast, Buddhism is not God-centred and the 'non-self' doctrine of Buddhism stands in contrast with the eternal soul in Christian religions. Both traditions are also considered minority practices in the demographic of the studied contexts, which we believe can highlight distinctive tensions in the meaning-making process.

To signpost our contributions: First, we provide a finegrained analysis relating to how meaningfulness is conceptualized by practitioners of different spiritual traditions. Our findings emphasize that meaningfulness is deeply connected to the different normative commitments and respective philosophies of each tradition. Importantly, we find meaningfulness is framed differently in each tradition: Buddhist practitioners frame meaningful work as temporal, transient and context-specific, whereas Quaker practitioners explain meaningfulness as something which is eternal and unaffected by context. Unlike Quaker practitioners, we show how Buddhist practitioners are willing to be contextually adaptive in order to find work meaningful. Second, we illuminate the significant tensions experienced in negotiation between organizational normativity and the kinds of normativity expressed in each of the two spiritual traditions. Our findings show that normative commitments and practices in spiritual traditions can influence individuals' meaning-making more evidently than organizational control mechanisms. However, this sometimes results in behaviours of resistance or disengagement.

The paper proceeds as follows. First, we review the literature and locate spirituality as both normative and subjectively interpreted. Second, we present our research method and findings. Third, we discuss our findings to elaborate both the theoretical and practical contributions of the study. Lastly, we conclude with pathways and directions for future research.

\section{Subjective/Normative Meaningful Work}

Meaningful work consists of a subjective sense of positive meaning that individuals derive from work, but also one grounded in an objectivity that shapes and legitimizes what is considered meaningful (Bailey et al., 2019a; Steger et al., 2013). Many scholars have defined meaningful work based on the extent to which work is subjectively meaningful to particular individuals (Bailey et al., 2019a; Bunderson \& Thompson, 2009; Renard \& Snelgar, 2016). Meaningful work has therefore been explored as an individual 
level phenomenon (Lepisto \& Pratt, 2017) and a property of human beings (Lips-Wiersma \& Morris, 2009). Existing studies have shown how individuals often need to satisfy personal motives, goals and ambitions (see Bailey et al., 2019a, 2019b for review). Subjective interpretations of meaningful work can be guided by individual characteristics, such as personality. For instance, Macey and Schneider (2008) found that a proactive personality can help individuals experience work in a positive and energetic way, and that some people are better at constructing meaning in work than others (Isaksen, 2000). People with more hardiness have the curiosity to find their experiences meaningful, while people with lower hardiness tend to find their environments meaningless or threatening (Kobasa \& Puccetti, 1983). Social and cultural contexts can also shape individuals' subjective interpretations of meaningfulness (Lepisto \& Pratt, 2017; Michaelson, 2009; Mitra \& Buzzanell, 2017) whereby individuals can develop their own accounts of the worthiness of the work based on social, cultural and institutional contexts (Lepisto \& Pratt, 2017, p. 112).

Michaelson (2019) argues however that subjective interpretations of meaningfulness do not adequately question if individuals can be wrong about their interpretation. In fact, Michaelson argues that subjectivism alone can be potentially harmful when it encourages an individual to engage in unproductive, counterproductive or destructive work, despite it being subjectively experienced as meaningful. For instance, voluntary work in a German refugee shelter was reframed in a dysfunctional way by volunteers to maintain their own sense of meaningfulness (Florian et al., 2019). On the other hand, people react to job surroundings based on their impression of the demands, hindrances and potentials of work (Lazarus \& Folkman, 1984) and there are circumstances when people may adapt to unfavorable circumstances that makes any self-evaluation of satisfaction distorted. Meaningfulness is not an inherent characteristic of a specific type of work and even though repetitive work can be considered as meaningless, alienating and dehumanizing (Fromm, 1990), it is still possible to subjectively construct meaning in repetitive work (Isaksen, 2000).

Meaningful work also comprises objective features shaped by institutional logics (e.g., Reinecke, et al., 2017), societal and cultural contexts (e.g., Lepisto \& Pratt, 2017; Michaleson, 2019; Mitra \& Buzzanell, 2017), and by organizations through job design, human resource management, values, culture or leadership (e.g., Cartwright \& Holmes, 2006; May et al., 2004). Social and cultural factors influence an individual's sense of meaningfulness. Weak formal institutions (e.g., law enforcement), for example, can influence meaning-making resulting in tensions between the notion of relational ethics and personal struggles in addressing moral issues (Vu, 2021). Organizations may, however, control or prescribe meaning and subvert an individual's subjective meaning-making process (Lips-Wiersma \& Morris, 2009; Michaelson et al., 2014). Such potentially manipulative or emotivist approaches to leadership (Sinnicks, 2018) can control meaning and trap employees into accepting harmful working conditions which can lead to a sense of alienation (Bailey et al., 2017; Lips-Wiersma \& Morris, 2009), or highlevels of adaptive preference (Nussbaum, 1997; Sen, 1985) whereby individuals may revise down their expectations in which work can be meaningful ( $\mathrm{Vu}, 2020)$.

Meaningfulness as a normative concept (Seachris, 2013) can help to shape a standard of objectivity. Normative concepts are closely related to philosophical ethics (Michaelson, 2019). When shaped by normative commitments, work can be socially meaningful when employees have prosocial motivations (Grant, 2007; Grant et al., 2007), a desire to make a positive difference in others' lives as well as to develop good character and a virtuous disposition (Beadle \& Knight, 2012). A normative sense of meaningful work involves an understanding of how work itself can be a contributor to a good life that gives individuals objective moral reasons to pursue meaningful work, and to impose moral obligations on institutions and organizations to provide such work (Michaelson, 2019).

Normative theorists (e.g. Selznick, 1948) emphasize the role of social obligation, values, and norms of how things should be done (Scott, 1995). In exploring normative accounts of meaningful work, much of the literature has mostly focused on the effects of institutional, social and cultural factors (e.g., Lips-Wiersma et al., 2020; Michaelson, 2019; Yeoman, 2014). For instance, institutional logics can foster moral schemes and features which legitimize an individuals' sense of worth (e.g., Reinecke et al., 2017, p. 41). Stein et al. (2019) found that institutional framing can influence an individuals' self-actualization and development, affecting their sense of meaningfulness (Stein et al., 2019). Meaningful work can also be normatively justified as an object of political action constituted by goods of autonomy, freedom and dignity (Yeoman, 2014). An individual's sense of meaningfulness is also culturally created and transmitted (Baumeister et al.., 2013, p. 506) because expectations of meaning differ across cultures (e.g., Harpaz \& Fu, 2002; Lysova et al., 2019). For instance, Confucian ethics can influence normative motives at work (e.g., Busse et al., 2018; Chu \& Vu, 2021; Kang et al., 2017). In countries with more individualistic and capitalist values such as the United States, societal expectations for subjective meaning from work can be higher than collectivist cultures where work could be seen as a means to an end to support family and community rather than an end in itself (Lysova et al., 2019). 


\section{Spirituality and Meaningful Work}

One important aspect of normativity is spirituality which consists of sets of beliefs, ethics, commitments, meanings and values to structure good living (Helminiak, 2011). Spirituality enables a person to develop good moral habits (Cavanagh \& Bandsuch, 2002). Studies often indicate that individuals locate their spirituality as a central feature of their pursuit to find meaning or purpose in life (LipsWiersma, 2002; Rosso et al., 2010). Spirituality underpins their appetite to contribute to the greater good (Bailey et al., 2019a), to facilitate "an authentic connection between their work and a broader transcendent life purpose beyond the self" (Bailey \& Madden, 2016, p. 55).

However, while existing literature regards meaningful work as one element of spirituality at work (Bailey et al., $2019 b$ ), little is known about how the tradition-specific normative commitments or philosophical ideas of different spiritual traditions shape subjective interpretations of meaningful work. In particular, when connecting meaningful work to spirituality, most studies treat spirituality as a monoculture (e.g., Ahmad \& Omar, 2016; Pardasani et al., 2014). Notable exceptions are Adawiyah's and Pramuka's (2017) study of the Islamic tradition, and Tablan (2019) who associates the Buddhist notion of 'right livelihood' to meaningful work. However, we are unaware of any comparative studies thereby limiting the potential for 'cross-cultural dialogue' on meaningful work (Michaelson et al., 2014, p. 88). This kind of comparative dialogue is important because different spiritual traditions reflect different philosophies of life that shape an individual's understanding and interpretation of meaningful work in different ways (Cavanagh \& Bandsuch, 2002). The tensions between spiritual practices and organizational, institutional and societal constraints are important parts of a negotiation process of meaning-making (Lepisto \& Pratt, 2017; Mitra \& Buzzanell, 2017; Vu, 2020), yet much remains to be explored to further understand how moral dilemmas and spiritual-enacted responses differ in different spiritual traditions that can further contribute to the conceptualization of normative accounts of meaningful work.

\section{Overview of the Studied Spiritual Traditions}

We chose the Buddhist and Quaker contexts to study for a number of reasons. First, Buddhism and Quakerism share epistemic standards relating to the primacy of personal experience. However, Quakerism has Christian roots and a theology grounded in finding unity with God (Dandelion, 2008), whereas Buddhism is not God-centred and its philosophy and practice are based on the fundamental understandings of the truths and sources of suffering. Moreover, both traditions are minority practices in the demographic of the studied contexts, which we believe can highlight distinctive tensions in the meaning-making process. For instance, Buddhists account for $16.2 \%$ of the Vietnamese population compared to folk religions (45\%) and people who do not follow any religious traditions (Pew Research Center, 2020). However, there has been a rising phenomenon of engaged Buddhism in the country impacting on business practices and the personal struggles associated with applying Buddhist practices in organizations (Vu, 2021; Vu \& Tran, 2021). Similarly, Quakerism is a minority religion in the UK with around 20,000 members (Dandelion, 2014). However, despite their small size, Quakers have had a significant impact on ethical approaches to industry and commerce (eg, Walvin, 1997).

Buddhism is a philosophy with an ethical and moral way of living life rather than a conventional religion (Cooper \& James, 2005; Johansen \& Gopalakrishna, 2006; Marques, 2010). Buddhist practices are fundamentally based on the Four Noble Truths (Sanskrit: catvāri āryasatyāni; Pali: cattāri ariyasaccāni) (Bodhi, 1984) to understand sources of suffering and the 'right' principles (e.g., right view, right intention, right speech, right action, right livelihood, right effort, right mindfulness, right concentration) of the Noble Eightfold Path (Sanskrit: āryāșțāngamārga; Pali: ariyo atțhangiko maggo) that guide individuals to overcome ignorance and suffering by defeating excessive attachment to one's own ideology through stages and processes of self-transformation. Buddhist practices embrace compassion (karun $\bar{a})$ as the aim of personal transformation; and aim at wisdom accumulation to enable practitioners to help others alleviate their pain or suffering (Dalai Lama, 1995; Rinpoche, 1992) and to enhance social capital (Burton \& $\mathrm{Vu}, 2021$ ). Buddhist practices are also guided by the notion of understanding:

Impermanence (Pāli: anicca; Sanskrit: anitya)—considering all phenomena as impermanent and empty of intrinsic existence (Thich, 1999). In this sense, all phenomena are constantly changing even in meaningful moments of time; and anything that resembles an intrinsic existence of the self or phenomena cannot be located in time and space (TsongKha-pa, 2004). Without a fixed self, individuals are more capable of change in response to the impermanent nature of phenomena (Harvey, 2000, p. 34).

Dependent arising (Sanskrit: Pratittyasamutpāda; Pali: Paticcasamuppāda) - refers to the nature of the universe whereby all phenomena are interwined and all mental and physical states arise from and depend on conditions (Harvey, 2000, p. 435). Individual betterment and social good on the other are fundamentally interrelated and interdependent (Rajavaramuni, 1990, p. 31).

Buddhist practice is a personal experience, a process of self-transformation, and a reflexive spiritual journey where one learns to let go of self-serving pursuits. Without continuous practice and experiences of failure ( $\mathrm{Vu}, 2021)$, one cannot experience the 'truths' in Buddhism. The practice of 
Buddhism is embedded in personal experience since there are variations of practice and different interpretations. In the Brahmajāla Sutta, the Buddha considers the 'sixty-two' philosophical views as all paths to liberation and these different views offer various different meditation techniques and religious disciplines (Rhys-Davids, 1899; Schroeder, 2004). Buddhist teachings (eg, the Dharma, including notions of dependent arising, non-self, impermanence, etc.) were referred to by the Buddha as a 'raft', nothing more than provisional devices through which to help others, and which cannot be applied in the same way in all situations and contexts. The 'right' way is determined by karmic disposition and context (Schroeder, 2004). The Buddha demonstrated that the Dharma is a type of karmic reasoning, with a variety of delivery forms known as skillful means (Kern, 1989; Lindtner, 1986). This highlights how normative inquiry in Buddhism is embedded in a contextual approach which is more pragmatic and functional rather than propositional and is without fixed evaluative criteria (Schroeder, 2004, 2011). Therefore, though Buddhist practices are based on the fundamentals of the Dharma, they are subject to each practitioners' subjective understandings and contextual applications.

Quaker theology is also diverse, varied and 'liquid' (Collins \& Dandelion, 2014), although central to Quaker theology is the idea of the Light Within implanted by God in every person and a readiness to answer that of God in another (Dandelion, 2004). Given that a Light Within is implanted in each and every person, Quakers have no priesthood and widely reject the sacred/secular binary, reflecting the presence of the divine in both 'worldly' and 'religious' activity (Muers \& Burton, 2019). Burton and Sinnicks (2021) remarked that this continuity of inner and outer life is deeply important in Quaker theology.

While Quakerism has Christian roots, Quakerism affords primacy not to creed or scripture, but to 'experimental' ways of knowing; claims to knowledge are based on collective discernment of right action (Muers, 2015, p. 15) which is known through a dynamic interaction between individual and community experience (Muers \& Burton, 2019), guided and shaped by the Quaker testimonies to peace, truth, integrity, simplicity, and equality. Testimony relates to the pattern of life to which Quakers subscribe and reflects an outward expression of an inner orientation to God (spirit); what Quakers do is more a statement of faith than words (Burton \& Bainbridge, 2019; Scully, 2009). Personal experience is thus made sense of and evaluated in the context of the Quaker testimonies (Muers, 2015; Muers \& Burton, 2019).

The testimonies are "storied and shared traditions" (Burton et al., 2018, p. 360) that promote standards of goodness that indicate the good life. In Quaker Studies, Scully (2009) reported that virtue ethics is the preferred ethical framework for UK Quakers, and that Quakers would reject a deontological or utilitarian approach to ethics due to a rejection of epistemic closure (Dandelion, 2004) and the primacy that Quakers grant to personal experience and experiential ways of knowing over creed or scripture (Muers, 2015). Further, the value Quakers' place on social justice is unlikely to sit comfortably with utilitarian ethics. While the continuity of spiritual and social life is central to "Quaker morality" the interplay between personal and community experience creates a potential space for a subjective interpretation of the good life.

\section{Methodology}

We collected interview data from two cohorts of individuals who described themselves as either Buddhist or Quaker, and who held a leadership or managerial role in a profit or nonprofit organization. We recruited thirty-six Buddhist participants in twenty organizations, who were all practitioners in their daily lives and in the work-place context. Many of the Buddhist practitioners followed the Vajrayana and Mahayana tradition (unlike the Theravada school which is more individualistic in attaining liberation). The Mahayana and Vajrayana paths facilitate not only individual progression but also through doing good for others (Ray, 2002) through skillful and contextual approaches to spiritual practice which are more practical in complex business contexts. The Buddhist participants were recruited by snowballing between 2018 and 2019, and interviews took place in 2019. We selected Vietnam owing to the rising 'Engaged Buddhist' movement in the country that facilitates Buddhist practices in organizations (Vu, 2019; Vu \& Tran, 2019). We also recruited thirtyfour Quakers from across twenty-three organizations. The participants were either members or regular attenders of a UK Quaker meeting associated with the Religious Society of Friends (Quakers), and all participants were recruited at a UK Quakers \& Business conference held in London in 2017. The data collected for this study forms part of a wider study of UK Quakers that covered practitioner interpretations of self-identity, morality and meaningful work (see Burton \& $\mathrm{Vu}, 2020$ ). We selected the UK as representative of a Liberal Quaker tradition (Dandelion, 2017). The profile of our interviewees is shown in Table 1.

Semi-structured interviews were utilized to collect data in both cohorts, and each interview was conducted in a private meeting room for about one hour at the participants' place of work. We invited participants to tell us about their experiences of meaningful work. Thus, we located the interview within the field of meaningful work, but allowed any direct connection related to spirituality/religion to emerge spontaneously during the interview process. We avoided creating a formal interview schedule, preferring to explore issues and themes as they emerged during the interview process. Follow-up questions, therefore, varied in each interview in 
Table 1 Respondents' information

\begin{tabular}{|c|c|c|c|c|}
\hline Person reference & Gender & Position & $\begin{array}{l}\text { Company } \\
\text { reference }\end{array}$ & Sector \\
\hline B1 & M & Regional director & V1 & Advertisement \\
\hline B2 & $\mathrm{F}$ & HR manager & $\mathrm{V} 2$ & Construction \\
\hline B3 & M & Marketing manager & & \\
\hline B4 & $\mathrm{F}$ & Project lead & & \\
\hline B5 & M & Project manager & V3 & Business consultant \\
\hline B6 & $\mathrm{F}$ & Financial manager & & \\
\hline B7 & M & Supervisor & V4 & Manufacturing \\
\hline B8 & $\mathrm{F}$ & Team leader & & \\
\hline B9 & $\mathrm{F}$ & $\mathrm{R} \& \mathrm{D}$ supervisor & V5 & Manufacturing \\
\hline B10 & M & Branch manager & & \\
\hline B11 & M & Relationship manager & V6 & Banking and finance \\
\hline B12 & $\mathrm{F}$ & Customer service supervisor & V7 & Business consulting \\
\hline B13 & M & Specialist & V8 & Business law \\
\hline B14 & $\mathrm{F}$ & Consultant & V9 & Pharmaceutical \\
\hline B15 & M & Production manager & & \\
\hline B16 & M & Consultant & V10 & Hospitality \\
\hline B17 & M & Specialist & V11 & Media \\
\hline B18 & M & Team leader & & \\
\hline B19 & $\mathrm{F}$ & Financial manager & & \\
\hline B20 & $\mathrm{F}$ & Deputy manager & V12 & Telecommunication \\
\hline B21 & M & Marketing specialist & V13 & Health service \\
\hline B22 & $\mathrm{F}$ & Accountant & & \\
\hline B23 & $\mathrm{F}$ & Financial advisor & & \\
\hline B24 & M & Relationship advisor & V14 & Publishing \\
\hline B25 & $\mathrm{F}$ & Supervisor & V15 & Hospitality \\
\hline B26 & $\mathrm{F}$ & Customer service manager & V16 & Information technology \\
\hline $\mathrm{B} 27$ & M & Marketing consultant & & \\
\hline B28 & M & Lead trainer & V17 & Insurance services \\
\hline B29 & $\mathrm{F}$ & Consultant & V18 & Construction \\
\hline B30 & $\mathrm{F}$ & Consultant & & \\
\hline B31 & M & Product specialist & V19 & Pharmaceutical \\
\hline B32 & $\mathrm{F}$ & Product representative & & \\
\hline B34 & $\mathrm{F}$ & Branch manager & & \\
\hline B35 & $\mathrm{M}$ & IT specialist & V20 & Banking and finance \\
\hline B36 & M & Product developer & & \\
\hline Q1 & M & Production manager & $\mathrm{U} 1$ & Chemicals \\
\hline Q2 & M & General manager & $\mathrm{U} 2$ & Hospitality \\
\hline Q3 & $\mathrm{F}$ & Store manager & $\mathrm{U} 3$ & Retail \\
\hline Q4 & $\mathrm{F}$ & Assistant store manager & & \\
\hline Q5 & $\mathrm{F}$ & Marketing manager & $\mathrm{U} 4$ & Publishing \\
\hline Q6 & M & Marketing manager & & \\
\hline Q7 & $\mathrm{F}$ & Theatre manager & U5 & Arts \\
\hline Q8 & $\mathrm{F}$ & Marketing manager & & \\
\hline Q9 & $\mathrm{F}$ & Consultant & U6 & Management consultancy \\
\hline Q10 & M & CEO & & \\
\hline Q11 & $\mathrm{F}$ & IT manager & & \\
\hline Q12 & $\mathrm{F}$ & CEO & $\mathrm{U} 7$ & Food \\
\hline Q13 & M & Director & & \\
\hline Q14 & M & Investment manager & U8 & Financial services \\
\hline Q15 & $\mathrm{F}$ & Director & U9 & Property \\
\hline
\end{tabular}


Table 1 (continued)

\begin{tabular}{lllll}
\hline Person reference & Gender & Position & $\begin{array}{l}\text { Company } \\
\text { reference }\end{array}$ & Sector \\
\hline Q16 & F & Marketing director & U10 & Education \\
Q17 & F & Membership manager & & \\
Q18 & M & Director & U11 & Enterprise \\
Q19 & M & Consultant & U12 & Management consultancy \\
Q20 & M & Partner & U13 & Law \\
Q21 & M & Partner & & \\
Q22 & M & Partner & U14 & Law \\
Q23 & F & Manager & U15 & Hotel \\
Q24 & M & CEO & U16 & Hotel \\
Q25 & M & Director & U17 & Conferencing \\
Q26 & F & Director & U18 & Conferencing \\
Q27 & M & CEO & U19 & Conferencing \\
Q28 & F & Director & U20 & Financial services \\
Q29 & M & Non-executive director & U21 & Financial services \\
Q30 & M & Director & U22 & Manufacturing \\
Q31 & F & Company secretary & & \\
Q32 & F & Executive assistant & & \\
Q33 & F & Manager & U23 & Arts \\
Q34 & F & Manager & & \\
\hline
\end{tabular}

order to allow us to more deeply explore issues that were of importance to each participant. The interviews in Vietnam were conducted and transcribed verbatim in Vietnamese by the first author and double-translated in English by the first author and a translation agency.

Template analysis was used to analyze the transcribed interview data. Our approach followed suggestions by King $(1998,2004)$ which has gained traction in multiple disciplines including management and organization studies (e.g., Burton \& Galvin, 2018). Template analysis is a flexible type of thematic analysis that emphasizes hierarchal coding but balances structure with epistemological flexibility to adapt it to the needs of a particular research study. We approached our template from a contextual constructivist perspective (Madill, et al., 2000).

Our approach to creating templates proceeded as follows: First, we examined the Buddhist and Quaker data separately in order to generate two separate templates. For each, we avoided pre-defining a priori themes from the extant literature, although our creation of the initial template was guided by our research question, and so we were particularly interested in 'interpretations', 'tensions' and 'responses' in the data. We began by reading all of the transcripts in full to orientate ourselves to the data (Brooks, et al., 2015). We then selected a sub-set of the interview transcripts (six for each template) and utilized NVivo11 to develop an initial template. Based upon our preliminary reading, we recognized some similarity in participant accounts in each respective data set, and thus we felt confident that selecting six transcripts from each data captured a good cross-section of the issues and experiences covered in the data as a whole. Each of the six selected interview transcripts were organized into meaningful clusters, and we began to define how they related to each other, including hierarchical relationships, with narrower themes nested within broader ones. We analyzed each transcript separately one at a time, and differences in coding were resolved through dialogue and discussion between the authors. This proved invaluable as it forced each of the authors to justify the inclusion of each theme, and to clearly define how it should be used.

Once we had an initial template for each of the two data sets, we proceeded to analyze the remainder of the data, three transcripts at a time. During this phase, the initial template was modified after each set of three transcripts as new themes emerged or other changes to the templates were made. As changes were made, previously analyzed interview transcripts were re-examined, and this iterative process continued ad-finetum until we reached a position where we felt the templates represented the data. Once we had two final templates, we then examined them in two ways: (1) each of the two templates was examined for integrative themes (King, 2004)—-themes that spanned several clusters-that permeated the data set; (2) We then cross-analyzed the two data sets to identify lateral integrative themes that permeated the whole data set. The integrative themes and differences in coding are shown in the appendix (Table 2). 


\section{Buddhist Practices/Principles Influencing Normative Accounts of Meaningful Work}

\section{Transient and Temporal}

In defining meaningful work, Buddhist practitioners highlighted some Buddhist principles/practices from which normative accounts of meaningful work were drawn. The Buddhist worldview emphasizes the transient nature of the universe based on the notion of impermanence. Participants emphasized the transient nature of meaningful work based on the notion of impermanence. For example:

There is no definite definition of meaningfulness and meaningful work in my mind. Things change every second because everything is impermanent. Just yesterday, I was happy to get a meaningful deal done. Today the contractors came back with some underlying conditions that they forgot to mention that changed everything. The meaningful deal is no longer meaningful (B4V2)

In addition, based on the notion of non-attachment as the foundation of Buddhist practices, participants rejected the need to find meaningfulness:

Being obsessed to get a job that is meaningful can be suffering. I mean there is no such thing as permanent moments of meaningfulness to seek for. You can experience meaningful moments for a while before they disappear. The search can reflect a constant desire and constant suffering. (B15V9)

This temporal understanding of meaningful work affected the way participants perceived the importance of ethics at work. For instance:

Making an ethical and right choice is also impermanent and it does not guarantee long-term meaningfulness. We reported an unethical business transaction of one of business partners. It was difficult but seemed to be an ethical move at that time. But then that action also took away more than 300 jobs from people. So being ethical and moral does not necessarily mean meaningfulness. (B34V19)

\section{Moral Accounts}

In guiding the normative accounts for meaningful work, participants shared that they relied on Buddhist principles/ practices. For instance, the Noble Eightfold Path shaped participants' meaning-making in doing the 'right' thing:

How you treat others reflects how well you can practice Buddhism. It is important to live morally, showing compassion to others, which are the basic principles every Buddhist lives by: right intention, right action, and right livelihood. (B12V7)

I always follow the guidelines of the Noble Eightfold Path. It helps me to act rightly, to be more considerate for others not just myself, which helps me appreciate more things at work and find meaning in them. (B29V18)

Extending the notion of 'right livelihood', participants expressed that a sense of meaningfulness is derived from the Buddhist notion of compassion. This interpretation involves a willingness to sacrifice personal interests. For example:

Meaningfulness comes from the ability to help others, to bring benefit to others rather than yourself. (B36V20)

Less is sometimes more. I felt really meaningful when we all sacrificed half of our salaries for a month to contribute to the project to fund a year of education for minority orphans in one of the poorest rural provinces of the country. (B29V18)

Buddhist practitioners also demonstrated how their intent and behaviours are negotiated against the depending arising principle, rejecting individual pursuits of meaningfulness as they can reflect desires leading to suffering based on the Four Noble Truths. For instance:

Having something meaningful at work for myself only is greed, which is not meaningfulness but suffering in Buddhism. It is suffering because first of all that sense of meaningfulness is temporal, not permanent so if we are too attached to that individual sense of meaningfulness, we suffer when we lose that sense. It also depends on others because obviously I cannot work alone in all projects without being supported by my colleagues and my organization. So it is fair to say that a sense of meaningfulness at work is not cultivated by one individual alone, it has a depending nature. (B5V3)

Participants also clarified that Buddhist practice is an individual practice but not for individualistic purposes. Its meaning comes from learning to interact with others. It cannot be mastered without being exposed to interdependent contexts:

Buddhism is all about exploring the truths by learning from others, interacting with others and from being exposed to impermanent and challenging contexts. It is an individual practice but cannot be achieved in separation with others. Dealing with conflicts with colleagues, clients and competitors is all part of that meaningful journey. I learn to respond and deal with challenges in my own way, based on my capabilities and skills but not in isolation. (B34V19) 


\section{Moral Dilemmas in Subjective Interpretations of Meaningful Work}

While participants expressed that Buddhist principles/practices guided their meaning-making at work, they also highlighted the dilemmas they faced when they tried to negotiate their subjective interpretations of meaningfulness in the work context. Participants expressed dilemmas in how their interpretations of meaningful work clashed with the work context:

I tend not to define meaningfulness and I understand that moments of meaningfulness can become meaningless very easily. But my project group was very keen on considering bonuses for group performance as meaningful. They are willing to be inauthentic with customers to achieve that. I did not share the same viewpoint with others. (B11V6)

Such a clash was experienced as uncomfortable. However, Buddhist participants also recognized that they were too concerned about how they felt and how they were attached to what others think about them. For instance:

Sometimes I wonder whether trying so hard to pursue meaningfulness is meaningfulness in itself. I am still attached too much to how others feel about my actions and how I see as right and wrong. I am certain that I am far from being 'free'. (B14V9)

Participants shared that meaningfulness often comes at the price of having to sacrifice personal values that they hold on to:

Bribing is unethical. Everybody knows that for sure and as a Buddhist, it is important to show right intention and right action $[\ldots]$ However, in practice, it is not always possible to maintain such principles [...] I had to let go of my personal and spiritual values to pay the lobbying fees for a medication project to help patients [...] being able to help is a meaningful outcome but it did not come without a 'price'. (B15V9)

Participants highlighted that certain compromises had to be made, particularly given the non-questioning cultural norms in workplace. For instance:

I realized that when I show compassion too much, I can also lose my opportunity to voice up my opinions or to help others to be aware of their wrongdoings or mistakes and learn from them. So perhaps, not being compassionate is sometimes more meaningful. In Vietnam, being critical is not the best practice and can be considered as hostile. People can take it very personally which can have detrimental effect on relationships. We have a high-power distance culture in our company and my colleagues are used to the non-questioning cultural norm where criticality was considered offensive and personal as people tend to be less direct to maintain productive relationships and networks. (B25V15)

Compromises and personal struggles were explained to be part of the Buddhist journey:

Personal struggles and compromises are the very first steps that I had to go through to get to know what Buddhist practices really mean. I have no doubt that they are part of the journey, which was extremely meaningful both in my professional life and in my daily life. Overcoming the fear of having to compromise is the practice of non-attachment. Embracing struggles is part of the Buddhist journey. (B1V1)

\section{Buddhist-Enacted Responses to Moral Dilemmas}

Participants shared how they struggled with different dilemmas in their justification for meaningful work. However, they also indicated Buddhist-enacted responses to address those issues.

\section{Skillful Means-Skillful Negotiations with Context-Sensitivity}

Impermanence challenged participants interpretations of meaningful work. However, it also guided participants towards a more flexible approach in defining meaningful work. This was further emphasized by the practice of skillful means, a technique that many Buddhist apply to contextualize their Buddhist practices flexibly in a work context. Participants demonstrated how they used skillful means to overcome their struggles, highlighting that sticking to a particular interpretation of 'right action' or 'right intention' is not useful. Understanding context and letting it decide what is 'right' in that particular context is more practical and meaningful.

Doing something meaningful is not about justifying that I did something right or my intentions were good. It is more about if I have been able to address the situation skillfully that produced the best outcome. I always look at the outcomes. Having a good intention to help out an employee does not solve the problem. I need to teach them, criticize them and even let them make mistakes to learn from. Doing things right is not the same as doing things skillfulty. Rejecting the common norm of gift-giving or favour-exchange in Vietnam is not a wise decision. Without network and relationships, I do not have the needed resources to help employees and the community. Buddhism provides you with the means to use, you just need to use them skillfully 
which involves being able not to be attached to them and stop defining what is 'right' because what is right should not be about what I believe is right but should be decided by the context. (B20V12)

The example quotation highlights a key philosophical idea that contributes to the way meaningfulness is conceptualized by Buddhist practitioners as it helps them move away from dilemmas of having to decide what is (un)ethical. The above participant relied on the notion of karma ${ }^{1}$ and karmic reasoning ${ }^{2}$ to justify the prioritization of social outcomes over 'right action'. The participant stressed that good intentions have to be accompanied by a skillful adaptation and response to context. Due to the culture of gift giving and favour exchange in the country, sometimes 'questionable actions' were accepted as means to attain social outcomes. For example:

In bidding for a contract with local hospitals to distribute our medication packages to needed patients, we customized and lowered our price so that lower income patients could afford them. We followed and met all the required conditions. However, we could not overbid our competitors not because of our products' quality or cost, but because we did not pay the 'transactional cost' for the gatekeepers. So, it felt like we were unable to do anything meaningful to help patients when we did everything right. On another occasion, we followed our ancestor's saying 'Đồng tiền đi tru'ớc là đồng tiền khôn' (money paid in advance is wise money). It is not the 'right action' as we gave money to hospital officials but it worked and we could help patients. Sometimes, doing the 'right thing' and having the right motive alone do not always bring meaningful outcomes (B34V19).

Participants also shared experiences when a good motive and right action together but without skillful execution could not generate a sense of meaningfulness. Without understanding the culture of how business in done within the weak legal systems, good intent and right action are not always helpful to facilitate social benefit.

Following karmic reasoning, participants also showed less attachment to personal moral values to facilitate a more skilful approach to prioritize meaningful outcomes due to

\footnotetext{
1 An action, cause, or event will initiate outcomes in the form of other effects and events that can either be pleasant or unpleasant based on the initial events' good or bad intentions (Vu, 2021).

2 Three elements determined karmic consequences: the intention or motive, the act, and completion and outcomes of the final states of the act and karmic consequences include those for oneself and others, as well as both individual and collective karma (Garfield et al., 2015, p. 297).
}

the contextual impact of strong personal network culture influencing work outcomes. For example:

My role involves a lot of networking and teamwork. A success of a project relies a lot on networks, which are sometimes personal. So I need to maintain a good relationship with my team because sometimes their personal networks can help me to complete a project. Some team members have ways of doing things which they believe is meaningful to get the project done. Sometimes I do not find them ethical, but I guess I learn not to attach too much to how things are done but pay more attention to the meaningful outcomes of a project. (B17V11)

We see how most Buddhist participants prioritized collective outcomes, whereby the outcome of actions is based on "the extent to which craving, greed or delusions and/or aversions are embodied in the underlying motive and intent of the original action" (Daniels, 2007, p.160).

As long as the overall outcome brings benefit for the community, personal sacrifices in actions are acceptable. I am willing to take my own karmic consequences in bribing officials if that can bring benefit for the whole community. Meaningfulness for the whole community overrides personal desires. (B30V18)

They also highlighted that as long as 'wrong' actions were enacted with good intentions for collective social outcomes, they are justifiable as it reflects skillful adaptation to the local business culture.

I tend to prioritize my good intentions over right action to make it meaningful [...] my actions can be instrumental but if it can help the community, that is all that matters. We have spent years asking for a license to construct our recycling factory that can raise workers' awareness in how we will do things in the near future and educate the community about being responsible in recycling but we failed. But when I helped a local official's relative to get a job, with his phone call, we got it approved in a matter of days. Without being skillful to the 'network culture', opportunities can be lost. (B3V2)

However, there were also contexts where actions could not be justified as a social outcome was not achieved due to the impermanent nature of the context:

At that time, we were willing to pay off officials to approve our project as we believed that our project to build a free vocational training center for the local community will be helpful for those who were struggling to find a job [...] it is also a way for us to invest in future skilled labour for our company. However, part 
of our 'compromise' was to hand back the center for the local authorities to manage [...] we found that local officials received bribes to accept locals into the center, which was not our initial intent [...] we compromised ignorantly and our good intentions turned out to be meaningless $[\ldots]$ we need to be more skillful to deal with impermanence $[\ldots]$ (B4V2)

From the above quotes we can learn that either committing to or compromising the 'right action' does not necessarily bring collective social benefits. What is perceived as meaningful at first can become meaningless due to impermanency. Therefore, participants stressed that adhering to karmic reasoning as a moral standard needs to be contextualized with an appreciation of the notion of impermanence.

Being skilful in practicing Buddhism is not about playing safe to avoid mistakes or failures as failures are what make individuals experience personal transformation intellectually in Buddhism:

Meaningful moments are found in failures and we all learn from failures to become better. It is important to have such moments to know your limits and shortcoming. Buddhist practice is all about personal transformation and failures are meaningful ingredients [...] you cannot play safe to fit in and expect to gain wisdom. Wisdom comes from lessons and failure (B24V14)

Therefore, in the process of experiencing meaningful work, personal struggles and dilemmas are part of a process of gaining wisdom through personal experiences of transformation. It is that process that makes a meaningful journey at work:

Meaningfulness for me comes from my failed experiences. The more I failed, the more knowledge I gained about myself and the world, and the more I understood and applied Buddhist practices more wisely. (B10V5)

Acknowledging the role and experiences of personal moral struggles and dilemmas and learning from them does not mean that participants adapt to them unconditionally but accept that they exist and are part of the process to skillfully learn from them.

Skillfully attending to how meaningful work is shaped is based on the notion of non-attachment embedded in all Buddhist practices. Participants rejected the idea of having to fit in or to be attached to the need to meet others' expectations as it can reflect suffering:

[...] It is not about finding my own version of meaningfulness or finding meaningfulness through others' but about freeing myself from all attachments, being free from personal desires and others' expectations. (B11V6)
[...] Quitting the job which I personally find meaningless of unethical and get a new one is not the solution since I can neither control my new boss or colleagues nor can I can control the new working culture/norm at the new company. Skillfully adapting and learning to let go of expectations and desires is the solution to abandon suffering. (B26V16)

I learnt to accept that there are always different opinions about what is right and what is wrong and I respect that. I adapt to certain viewpoints/decisions when the context supports them but raise my voice when they are no longer fit the context. I learnt to let go of fulfilling expectations or the fear of being judged. Being able to let go is meaningfulness. (B8V4)

\section{Quaker Ethics Influencing Normative Accounts of Meaningful Work}

\section{Eternal and Omnipresent}

A recurring theme in our data was that meaningfulness was conceived as both eternal and omnipresent. The theme of finding the 'eternal' essence in work came across strongly in our data:

God is eternal, and we are all tasked with finding that which is eternal in everything we do. I try to find the meaning in the work I do and try to understand how that work contributes to building a better world (Q28U20)

Given the omnipresence of God, meaningfulness at work can arise in any place, in any job role, at any time, so long as work has a moral purpose and is interpreted in line with Quaker aims of building a better world.

So for me the purpose of work is how I find meaning. It doesn't matter what the job is, or what it looks like, or how much the salary is, so long as you are contributing to battling injustice in a small way. The job could be anything, but the purpose can't. (Q33U23)

Look, I am an administrator. And, many of friends think my job must be boring, mundane. Perhaps it is. If I looked at it as a set of tasks, yes it is. But, I know that my job reduces social disadvantage, offering opportunities to those who have no hope, I see a reflection of God in that moment (Q32U22)

For Quakers, even the most mundane roles can be imbued with meaning:

Meaning is everywhere, all the time. Even the most mundane work can have spiritual meaning. Working in an industrial estate or a poor neighborhood can have 
meaning. It is your mindset that matters, and whether you can find God in small things, unusual things (Q1U1)

\section{Moral Accounts}

The Quaker testimonies are central to understanding how meaning is conceptualized. For example, the Quaker testimonies were seen as deeply connected to assessing whether work is meaningful. In the following example, the social purpose of work is emphasized:

While any work can be potentially meaningful, the benefits from work should not be solely individual and personal. Work must have a social purpose that reflects building a fairer and more equitable world (Q2U17)

The social outcomes of meaningful work were emphasized as superior to individualistic aims, as the following exemplifies:

Meaning at work can never be fully realized if it centers upon self and ego. More money, more power or privilege are likely to erode meaning in the long-run. The key for me is to know that I am making a difference to others, to those experiencing structural disadvantage or those in need (Q13U7)

Further, the focus on the 'other' is related to theological ideas in Quakerism:

I find meaning not for myself but for others that suffer injustice and disadvantage. This means I need to supress my ego and respond to God in an another (Q9U6)

Participants offered numerous examples of meaningful work connected to particular Quaker testimonies. In this example, the testimony to equality is connected to meaning derived from work that tackles social disadvantage:

The testimony to equality is key to living out Quakerism. Work can only be meaningful when you are dismantling these...[social]...inequalities (Q16U10) We all need to live simply. This means, for me, a simple job without the entanglements of worrying about pay, power, privilege (Q6U4).

Living out the Quaker testimonies at work was also described as providing a sense of unity between professional and personal lives:

By fusing my professional and spiritual life, I now work entirely from a perspective of wholeness and service in life. I work with mindfulness and compassion. I emphasize integrity and values- led behavior, I question taken-for-granted practices, and have a real concern for equality and everyone having a voice. The Quaker testimonies are my guide (Q6U4)

In addition, the Quaker testimonies were reported to act as a guide for career choice and work behaviors:

Quaker values strongly influence my approach to my work life. I see myself as leading the organization towards positive change. The Quaker testimonies guide me in this endeavor (Q13U7)

Quakerism guides my choice of employment. I currently work for a charity and have scope to live out my values at work by working in service of others with less power and privilege (Q11U6)

In addition to connecting meaningful work to Quaker testimonies, meaningfulness was also directly connected to theological ideas that underpin Quaker ideals. Meaningful work should advance God's kingdom or God's purpose:

It is quite straightforward, meaningful work is any work that furthers the development of God's kingdom for all of God's people (Q24U16)

Gods morals are my morals [...] I can only find true meaning in work that fulfils God's purpose (Q2U2)

A number of participants also remarked that the Quaker phrase "That of God in everyone' helped them find meaning at work through the way in which they interacted with others:

We Quakers say 'finding that of God in everyone'. For me this plays out at work. If I can find that of God in another, and respond with grace to that presence of God, then work, like everything else, has meaning for me (Q3U3)

\section{Moral Dilemmas in Interpretations of Meaningful Work}

Our participants continually remarked that moral dilemmas occurred relating to tensions between pursuing meaningful work to generate social outcomes and a need for selffulfillment and status:

I guess a key pinch point I experience is letting go of selfish desires and ego. I often find myself thoughtlessly chasing promotion, more pay, and things like that when I know I should be prioritizing the difference I can make in the world (Q34U23)

I remember leaving a senior position in a FTSE100 company. The car went back, the parking space, the laptop, the phone, all the paraphernalia that comes with a senior job. It was weird. I sort of felt naked for a few hours. I was no longer Head of......and was about to take up a much-lower paid role in a small charity 
doing work with disadvantaged communities. It takes so getting used to- the loss of all that status-but the new role brings so much joy makIn the following example, the tension between self-actualization and pursuing work that provides social or moral outcomes exemplifies the tensions in our data:

A few years ago I applied for a new job and was verbally offered the role. I felt hugely uncomfortable, as a white man, being offered a senior role by white men. I questioned the diversity of the team and was told that they would 'be in touch'. They never did. While I am proud of my actions, I still struggle that this cost me dearly and I have my family and our comfort to think about too. Was it the right decision? I don't know (Q27U19)

I remember leaving a senior position in a FTSE100 company. The car went back, the parking space,the laptop, the phone, all the paraphernalia that comes with a senior job. It was weird. I sort of felt naked for a few hours. I was no longer Head of......and was about to take up a much-lower paid role in a small charity doing work with disadvantaged communities. It takes so getting used to- the loss of all that status-but the new role brings so much joy making a difference to those facing social disadvantage. I often think back to my old 'self' and the power and privilege I had and sometimes don't even recognize him. Mind you, I miss the company car! (Q19U12)

Tensions also arose due to the normative demands of organizations (exclusively profit-seeking organizations) that compete with a Quaker sense of morality. This occurred in relation to particular actions that were demanded:

I've been through a phase where I thought higher pay, nicer car, would kind of create meaning for me. But, more power often comes attached with tasks which are morally unacceptable. I had to make people redundant, impose pay freezes and so on as the quid pro quo of power. (Q21U13)

However, participants often reflected that compromise was never worth the cost:

Often, work-places ask you to do things which are really challenging. Such as make someone redundant, or as simple as put the organization before your family. This is extremely challenging, and I've reached the conclusion that compromise is never worth it in the long run. I know that if I felt my desk would be occupied by a new recruit within days, there is never any real loyalty (Q15U9)

\section{Quaker-Enacted Responses to Moral Dilemmas}

\section{Resistance and Moral Disengagement}

\section{Exiting}

Our participants remarked upon two distinctive strategies to respond to the moral dilemmas they encountered. For many, exiting the organization and pursuing alternate forms of work was conceived as the only viable route to preserve a sense of Quaker morality and avoid severe moral dissonance. For example:

My Quaker values inform my attitudes to work - I moved jobs to transform my outlook. I cannot any longer accept poor ethical practice. I resigned over the poor treatment of others (Q33U23)

A number of other participants suggested exiting the organization was related to a desire to pursue more socially-meaningful career choices:

I have worked with many great people, worked in great teams, but I remained empty and unfulfilled. It was all meaningless. To find purpose, I had to switch career to do work that tackled social disadvantage, injustice and inequality (Q25U17).

However, while some pragmatism was mentioned by a few respondents, many did not share this view:

Of course, there is some degree of pragmatism required, I still need to support my family and pay the bills (Q8U5)

The desire to maintain moral unity between professional and personal lives for vitally important for our participants. For instance:

Leaving my job was the only way to reconcile my Quakerism with my professional life. You know, when you are continually asked to do tasks that you find morally concerning, you can only do it for so long. Quakers say, 'wear thy sword as long as you can', meaning metaphorically disarm yourself as soon as your conscience. allows. Leaving my job was disarming myself of the emptiness that comes with working for a profit-seeking organization (Q27U19)

\section{Moral Disengagement}

The second distinctive strategy to respond to moral dilemmas involved compartmentalizing work tasks into subjective categories of meaningful' and 'meaningless', and morally 
disengaging from the latter, in order to preserve moral unity. For example,

To me my Quakerism is central to my moral identity. I can sometimes only uphold this at work by dissenting and disengaging at work (Q22U14)

Compartmentalization involved morally engaging with aspects of work that could be conceived as meaningful. For example:

I have to find some meaning at work. My day job is tiresome, money, money, money. I have to put this aside. For example, I try to get some meaning by volunteering for the occasional good things my employer does. Last month, I participated in a sleep out to raise money for the homeless. That was satisfying (Q11UK6).

My work gives me no meaning. Unless I can carve out some time to do the work I want to. Luckily, my boss recognizes this, and I can spend a few days each month working at a charity that works with disadvantaged groups (Q32U22).

In addition, many participants remarked how they tried to compartmentalize work tasks by purposely morally disengaging from tasks they perceived as immoral:

At work I am often faced with tasks that I find clash with my Quakerism. I do all I can to avoid them. It's a difficult ethical choice, but I try to spend more time doing things that are worthwhile, or at least neutral, and avoid the things I find ethically troubling. Dissenting and voicing concern is my strategy (Q4U3)

I try to spend my time at work on things that nurture my soul and the community. I volunteer, I get involved in community work, in outreach, and other things that support my Quaker faith. I do as little of my real job as I can get away with (Q19U12)

\section{Discussion}

The study highlights a number of theoretical contributions. First, our study contributes to the literature on normative accounts of meaningful work through a fine-grained comparative analysis of two different spiritual traditions and how they shape subjective interpretations of meaningful work. While spiritual traditions provide 'standards of goodness' (e.g., Helminiak, 2011; Michaelson, 2019; Michaelson et al., 2014) through key philosophical or theological ideas that influence meaning-making, there are fundamental differences between the two traditions that affect not only the character of meaning-making, but also the tensions experienced and how practitioners respond. Illuminating these kinds of connection allow us to deepen understandings of normative accounts of meaningful work.

In exploring the Buddhist and Quaker traditions, we found that both traditions emphasize moral standards to interpret meaningful work. For instance, Buddhist participants were guided by the Buddhist Noble Eightfold Path, and the notion of compassion and dependent arising. The Quaker tradition, on the other hand, provided a normative framing for interpretations based around key theological ideas such as 'That of God in everyone' and the normative content of the Quaker testimonies to peace, truth, integrity, simplicity, and equality.

Both traditions also present epistemic differences that influenced how our Buddhist and Quaker practitioners conceptualized and experienced meaningful work. Buddhist practitioners found meaningful work as transient and temporal based on the notion of impermanence and nonattachment in a sense that there is no definitive way of defining meaningfulness as all phenomena are impermanent and the pursuit and over-attachment to a sense of meaningful work can reflect personal desire and forms of suffering. Their expressions were framed by the Four Noble Truths, which highlights that excessive desires caused by ignorance can trap individuals into a need to achieve outcomes at any cost, leading to psychological burdens and suffering. Part of this suffering is caused by an individuals' illusion of an ultimate state of self and reality (Gampopa, 1998), failing to acknowledge the impermanent state of the phenomena. Such interpretations demonstrate the transient state of meaningfulness, which aligns with studies that have remarked that meaningfulness is an episodic state (e.g. Bailey \& Madden, 2017) and is subject to negotiation retrospectively over time (Mitra \& Buzzanell, 2017). The transient and temporal nature of meaningfulness was strongly influenced by participants' contextual subjectivity in responding to moral dilemmas following the practices of skillful means and impermanence, which emphasizes a contextual approach based on the fundamentals of the Dharma and an absence of fixed evaluative criteria (Schroeder, 2004, 2011).

In contrast, Quaker practitioners shared an eternal and omnipresent view of meaningful work. As God and God's truth are eternal and omnipresent, so Quakers viewed meaningfulness as eternal and omnipresent, so long as work has a social and moral purpose in line with God's purpose. For Quakers, therefore, Quaker theology and Quaker testimonies provide an external standard of goodness by which subjective evaluations of meaningfulness can be judged.

Given the similar moral and ethical purpose that Buddhism and Quakerism share, it was surprising to find such fundamental differences. These differences highlight that there are no universal spiritual-normative standards that can define meaningful work. Each of the traditions has particular 
philosophical or theological ideas that deeply influence personal conceptualizations of meaningfulness, and thus we might expect other deep connections to exist in other traditions, whether religious, spiritual or neither. Our comparative study contributes to further understanding the 'messiness of meaningful work' (Mitra \& Buzzanell, 2017, p. 4) by addressing and introducing the temporal versus eternal features of meaningful work. Our temporal vs. eternal categories appear as opposing conceptions of meaningfulness that are shaped by the different normative and theological epistemologies.

Second, the study contributes to the literature on the tension between organizational normativity and the kinds of moral normativity expressed in each of the two spiritual traditions. Both Buddhist and Quaker participants experienced similar contextual challenges and tensions relating to meeting the expectations of organizations or trying to fit in with organizational forms of meaningfulness.

Quaker participants tried to resist the kind of severe moral compartmentalization described by MacIntyre $(1999,2008)$. As Burton and Sinnicks (2021) noted, compartmentalization of the self is especially likely to arise in the context of work and leaves an individual unable to adjudicate between competing organizational and spiritual or normative demands. In the Quaker tradition, the theological idea of unity with God and an emphasis on continuity between the spiritual and social life was central to their conception of morality and enabled Quakers to move moral purpose beyond the contextspecificity of a situation and avoid "cross-context application of the virtues" (p. 7) in order that 'right' action is more easily discerned. Our findings therefore suggest that while organizational forms of normativity generated extreme tensions, the key Quaker ideas of unity and living a 'good life' resulted in high-levels of resistance and moral disengagement with the perceived unethical demands of organizations.

Buddhist practitioners, on the other hand, experienced tensions in dealing with overcoming attachment to moral values in order to make compromises to organizational forms of normativity. Unlike Quakers, Buddhist participants leaned towards compromising when there was a clash between moral values and organizational norms, and we theorize this compromise as related to transient interpretations of meaningful work. Moral struggles (eg, participating in bribery) are considered as part of the Buddhist journey to selftransform and accumulate wisdom (Purser \& Milillo, 2015; $\mathrm{Vu} \&$ Burton, 2020). Most scholarship on meaningful work argues that the powerful (e.g., organization) crafts meaning for the powerless (e.g., employees) (e.g., Bailey et al., 2019a; Tourish, 2019), by enforcing organizational practices (Bailey et al., 2016) or neo-normative forms of ideological control (Toraldo et al., 2019). However, the Buddhist practitioners in this study were not controlled by organizational normativity per se, but rather their willingness to compromise was based upon the Buddhist principle of non-attachment, karmic reasoning as a form of skillful means and that concepts such as meaningfulness are impermanent. Therefore, normative forms of control by organizations did not represent a 'symbolic manipulation of meanings' (Gabriel, 1999, p. 184) but rather unethical demands by organizations were conceived as opportunities to learn and transform.

Third, our study highlights how Buddhist and Quaker practitioners respond to moral tensions. These responses illustrated remarkably different levels of subjectivity. Buddhist practitioners applied Buddhist principles as skillful means in order to contextualize Buddhist practices to the work-place and overcome moral tensions. Whereas many spiritual traditions rely upon near-universal principles that are justified independently of their context, Buddhism explicitly incorporates the idea that circumstances and context should be taken into account when taking moral action-mirroring the idea that context influences decision making (e.g. Buckley, 2013; Kelley \& Elm, 2003). Thus, Buddhist teaching reaffirms how truth-values are only relative to the context of assessment and how any notions of right and wrong have contextual extensions reflecting moral relativism (Brogaard, 2008).

In our findings, skillful means was employed as a rhetorical means for expressing some versions of truth (Gombrich, 1996; Schroeder, 2011; Williams, 1989) with the rationale that all knowledge is ideology and its dissemination is only needed for certain contexts (Organ, 1954) as there is no Buddha to be sought, no way to be carried out, no Dharma to be gained (Watson, 1993, p. 61). Drawing from this notion of skillful means, our participants recognized that in a country like Vietnam with strong cultural norms of relationships and networks embedded in the workplace, it is important to be practical. For instance, bribery is a common practice $(\mathrm{Vu}$, 2021), which requires recognition that the practice of bribery cannot be 'undone' but rather must be used for skillful ends rather than questioning the morality of the practice (Shin et al., 2021). Buddhist participants were willing to reverse down their moral expectations to show a context-sensitive level of adaptivity similar to the notion of adaptive preference (Nussbaum, 1997; Sen, 1985) to fit in with cultural and organizational norms. Unlike Quakers, they explained that simply rejecting or quitting the uncomfortable working context does not represent a solution, since moving to another work context does not guarantee a meaningful work context. Adjusting individual adaptability to context was considered as a skillful means to master non-attachment and to experience the temporality of meaningful work. The temporal orientations of Buddhist participants were shaped by situational exigencies (Hitlin \& Glen, 2007) rather than using moral agency to resist the temporal experience of a situation or dismiss contextual influences (e.g., Bandura, 2001, 2006). 
It is important to highlight that high levels of contextual adaptability (e.g., accepting bribery, failures as lessons or unethical collective actions) activated by skillful means is not the same as Bandura's (1991, 1999) concept of moral disengagement as Buddhist participants morally engaged by prioritizing social outcomes over personal moral values based on the notion of karmic reasoning. Their meaningful experiences were individualized but not self-serving (Allan et al., 2019), guided by situational circumstances (Jones, 1991). Their moral justification in adapting to unethical actions did not involve euphemistic language to justify actions (Bandura et al., 1996) or blaming 'others' (organizational normativity) for bringing suffering on themselves (Bandura, 1991) as they considered moral struggles as necessary for transformative learning. Unlike situating the self within a broader social cognitive self (Bandura, 2011), Buddhist practitioners 'empty out' the self and agency is contextualized and exercised in a context-sensitive manner rather than being translated into mechanisms rooted in moral standards (Newman et al., 2020).

However, skilful means can also serve as a means of justification for harmful subjective interpretations (e.g., rationalization for bribery acts), which reflects Michaelson's (2019) claim that subjective interpretations of meaningfulness remain problematic when individuals can potentially be wrong about their interpretations. In our findings, the social and cultural context of work strongly shaped subjective interpretations of meaningfulness. Even when karmic reasoning was adopted as a moral standard to rationalize social outcomes over personal moral action, it was subject to a contextual interpretation of motives, action (means), and outcomes. Participants prioritized social outcomes and good intentions over 'right action'. As long as intentions prioritized social outcomes (e.g., distributing medical packages, building vocational training centres, etc.), constraining personal moral values and participating in unethical actions (e.g., paying off hospital officials, favour-exchange with officials, etc.) were justifiable. Unethical actions were considered as a skillful and contextual means to adapt to Vietnamese business culture.

The notion of impermanence was also important to our participants' moral reasoning. For example, while participants rejected the culture of gift-giving, favour-exchange, and acts of bribery, sometimes these unethical actions were tolerated in light of expected future social outcomes. However, our analysis indicates circumstances that compromising on 'right action' to respond to the social and cultural context could generate perceptions of meaningless when those intended social outcomes did not emerge. Our participants coped with these experiences of meaningless by drawing upon the notion of impermanence and the transience of meaningful work, and by reframing their karmic evaluation as based upon good motives and intention. In other words, the absence of social outcomes was justified because motives and intentions were 'right'. By justifying motives and actions using karmic reasoning as skillful means, our findings reflect Brogaard's (2008) conceptualisation of moral relativism in how any notions of right and wrong have contextual extensions. Contextual interpretations of meaningful work can be a matter of individual subjectivity (e.g., Michaelson, 2019) and our study shows how context and subjectivity can entwine within karmic reasoning.

Whereas Buddhist practitioners were willing to contextualize agency through karmic reasoning, Quakers embody a moral purpose beyond the context-specificity of a situation. When faced with (un)ethical choices, Quakers responded by resisting organizational demands through either avoiding the context (exiting the organization) or compartmentalizing work into subjective categories of 'meaningful' and'meaningless', and morally disengaging from the latter (e.g., see Newman, et al., 2020 for a review). Compartmentalizing work tasks and morally disengaging from meaningless work in this way indicates that Quakers' needed to minimize dissonance that would arise from moral compartmentalization (Burton \& Vu, 2020) and defend their moral agency to choose work that is meaningful to them. In other words, Quaker theology and testimony presents a strong moral framework that serves to both limit subjectivity in the work context and resist organizational normative demands. Further, while Quakerism seems to set the standards and conditions within which Quakers use agency to morally (dis)engage, the flip-side to the coin indicates that, from the perspective of the organization, Quakers may be willing to engage in non-conformist or even deviant behavior, an observation that sharply contrasts with existing workplace spirituality literature (e.g., Sheep, 2006).

\section{Conclusions and Avenues for Future Studies}

The study further extends comparative understandings of subjective/normative interpretations of meaningful work. Our findings highlight a dynamic interplay between subjective-normative interpretations of meaningful work guided by the commitments of the Buddhist and Quaker traditions.

Our study has a number of theoretical and practical implications for business ethics scholarship. While our study deepens an understanding of subjectivity and normativity in meaningful work in the Buddhist and Quaker contexts, various scholars have suggested that various spiritual or religious domains can be conceptualized as 'traditions' in the MacIntryian sense (Burton \& Sinnicks, 2021). There are also a number of traditions in the much broader sense: Buddhism, Marxism, and even Liberalism, for example. Our findings and contributions suggest a broader generalization to other traditions, religious, spiritual or otherwise. 
Normative commitments are likely to deeply shape interpretations of meaningful work and yet the extent to which normative commitments entwine with subjectivity would seemingly give prominence to the key philosophical ideas of the tradition. Our example of Buddhism closely relates subjectivity to the contextual-sensitivity associated with the practice of skillful means and karmic reasoning. This kind of contextual subjectivity may, as our study notes, give rise to interpretations that are considered by others in different contexts, cultures or traditions as unethical. Reductively assuming that because an individual is "spiritual", she would disengage from "unethical" actions is misguided. Further research may shine a light on studies that have found a relationship between religion/spirituality and unethical behaviour (Alshehri et al., 2020; Zhang, 2020). Our study shows how a deeper understanding of the normative content of the interplay between meaningful work and different traditions would greatly enhance this stream of scholarship.

Given our focus upon spirituality, we recognize that subjectivity is also influenced by a number of contextual factors that we have not had space in this paper to explore. Further research that explores how the different normative commitments of spiritual traditions entwine with social and institutional factors to affect meaningfulness would help advance scholarship. Studies in different cultures and where the focal spiritual tradition is a majority or contested practice would be especially intriguing.

Our study has a number of practical implications. For organizations, our Quaker case analysis suggests that spiritual practitioners could be a destabilizing force in the workplace if they perceive work as meaningless. Moral disengagement with work would appear to be a significant risk. Leaders are encouraged to have personal conversations around the content of meaningful work with workers in order to avoid individuals exiting the organization or engaging in non-conformist behavior. In the Buddhist case analysis, our study suggests that even when individuals show high levels of adaptability and context-sensitivity, it is possible that individuals may still experience tensions and personal struggles. In both cases, showing normative power is unlikely to prove fruitful.

Our study is not without limitations. We have examined two particular spiritual traditions with distinctive practices and commitments. Future studies may of course benefit from examining other spiritual or religious traditions that may deepen understandings further. Our participants primarily held managerial and leadership roles, and perhaps these individuals were in a fortunate position to practice their spirituality at work and make choices about which work they engaged in. How spiritual individuals in other types of non-managerial work experience meaningful work deserves further attention.

\section{Appendix}

See Table 2. 
Table 2 Coding table

\section{Buddhist practices/principles influencing normative accounts of meaningful work}

Transient and temporal

There is no definite definition of meaningfulness and meaningful work in my mind. Things change every second because everything is impermanent (impermanence). Just yesterday, I was happy to get a meaningful deal done. Today the contractors came back with some underlying conditions that they forgot to mention that changed everything. The meaningful deal is no longer meaningful (B4V2)

Being obsessed (TFNT) to get a job that is meaningful can be suffering. I mean there is no such thing as permanent moments (impermanence) of meaningfulness to seek for. You can experience meaningful moments for a while before they disappear. The search can reflect a constant desire (TFNT) and constant suffering (TFNT). (B15V9)

Making an ethical and right choice is also impermanent (impermanence) and it does not guarantee long-term meaningfulness. We reported an unethical business transaction of one of business partners. It was difficult but seemed to be an ethical move at that time. But then that action also took away more than 300 jobs from people. So being ethical and moral does not necessarily mean meaningfulness. (B34V19)

\section{Moral accounts}

How you treat others reflects how well you can practice Buddhism. It is important to live morally, showing compassion (compassion) to others, which are the basic principles every Buddhist lives by: right intention, right action, and right livelihood (TNEFT). (B12V7)

I always follow the guidelines of the Noble Eightfold Path (TNEFP). It helps me to act rightly (TNEFP), to be more considerate for others not just myself, which helps me appreciate more things at work and find meaning in them. (B29V18)

Meaningfulness comes from the ability to help others (compassion), to bring benefit to others rather than yourself. (B36V20)

Less is sometimes more. I felt really meaningful when we all sacrificed (compassion) half of our salaries for a month to contribute to the project to fund a year of education for minority orphans in one of the poorest rural provinces of the country. (B29V18)

Having something meaningful at work for myself only is greed (TFNT), which is not meaningfulness but suffering in (TFNT)Buddhism. It is suffering because first of all that sense of meaningfulness is temporal, not permanent (impermanence) so if we are too attached to (non-attachment) that individual sense of meaningfulness, we suffer when we lose that sense. It also depends on others because obviously I cannot work alone in all project without being supported by my colleagues and my organization. So it is fair to say that a sense of meaningfulness at work is not cultivated by one individual alone, it has a depending nature (dependent arising). (B5V3)

Buddhism is all about exploring the truths by learning from others, interacting with others and from being exposed to impermanent (impermanence) and challenging contexts. It is an individual practice but cannot be achieved in separation with others (dependent arising). Dealing with conflicts with colleagues, clients and competitors is all part of that meaningful journey. I learn to respond and deal with challenges in my own way, based on my capabilities and skills but not in isolation. (B34V19)

Moral dilemmas in interpretations of meaningful work

I tend not to define meaningfulness and I understand that moments of meaningfulness can become meaningless very easily (impermanence). But my project group was very keen on considering bonuses for group performance as meaningful. They are willing to be inauthentic with customers to achieve that. I did not share the same viewpoint with others. (B11V6)

Sometimes I wonder whether trying so hard to pursue meaningfulness is meaningfulness in itself. I am still attached too much (non-attachment) to how others feel about my actions and how I see as right and wrong. I am certain that I am far from being 'free'. (B14V9)

Bribing is unethical. Everybody knows that for sure and as a Buddhist, it is important to show right intention and right action $(T N E F P)$ [...] However, in practice, it is not always possible to maintain such principles in practice [...] I had to let go of my personal and spiritual values (non-attachment) to pay the lobbying fees for a medication project to help patients [...] being able to help is a meaningful outcome but it did not come without a 'price'. (B15V9)

I realized that when I show compassion too much (non-attachment), I can also lose my opportunity to voice up my opinions or to help others to be aware of their wrongdoings or mistakes and learn from them. So perhaps, not being compassionate is sometimes more meaningful. In Vietnam, being critical is not the best practice and can be considered as hostile. People can take it very personally which can have detrimental effect on relationships. We have a high-power distance culture in our company and my colleagues are used to the non-questioning cultural norm where criticality was considered offensive and personal as people tend to be less direct to maintain productive relationships and networks. (B25V15)

Personal struggles and compromises are the very first steps that I had to go through to get to know what Buddhist practices really mean. I have no doubt that they are part of the journey, which was extremely meaningful both in my professional life and in my daily life. Overcoming the fear of having to compromise is the practice of non-attachment (non-attachment). Embracing struggles is part of the Buddhist journey. (B1V1) 


\section{Buddhist practices/principles influencing normative accounts of meaningful work}

Transient and temporal

\section{Buddhist-enacted responses to moral dilemmas}

Skillful means-skillful negotiations with context-sensitivity

Doing something meaningful is not about justifying that I did something right or my intentions were good. It is more about if I have been able to address the situation skillfully $(S M)$ that produced the best outcome. I always look at the outcomes $(K R)$. Having a good intention to help out an employee does not solve the problem. I need to teach them, criticize them and even let them make mistakes to learn from. Doing things right is not the same as doing things skillfully $(S M)$. Rejecting the common norm of gift-giving or favour-exchange in a country in Vietnam is not a wise decision. Without network and relationships, I do not have the needed resources to help employees and the community. Buddhism provides you with the means to use, you just need to use them skillfully which involves being able not to be attached to them and stop defining what is 'right' because what is right should not be about what I believe is right but should be decided by the context (SM). (B20V12)

My role involves a lot of networking and teamwork. A success of a project relies a lot on networks, which are sometimes personal. SoI need to maintain a good relationship with my team because sometimes their personal networks can help me to complete a project. Some team members have ways of doing things which they believe is meaningful to get the project done. Sometimes I do not find them ethical, but I guess I learn not to attach too much to how things are done (non-attachment) but pay more attention to the meaningful outcome of a project $(K R)$. (B17V11)

As long as the overall outcome brings benefit for the community $(K R)$, personal sacrifices in actions $(K R)$ are acceptable. I am willing to take my own karmic consequences in bribing officials if that can bring benefit for the whole community $(K R)$. Meaningfulness for the whole community overrides personal desires $(K R)$. (B30V18)

I tend to prioritize my good intentions over right action $(K R)$ to make it meaningful [...] my actions can be instrumental but if it can help the community, that is all that matters $(K R)$. We have spent years asking for a license to construct our recycling factory that can raise workers' awareness in how we will do things in the near future and educate the community about being responsible in recycling but we failed. But when I helped a local official's relative to get a job, with his phone call, we got it approved in a matter of days. Without being skillful to the 'network culture' (SM), opportunities can be lost. (B3V2)

In bidding for a contract with local hospitals to distribute our medication packages to needed patients, we customized and lowered our price so that lower income patients could afford them. We followed and met all the required conditions. However, we could not overbid our competitors not because of our products' quality or cost, but because we did not pay the 'transactional cost' for the gatekeepers $(K R)$. So, it felt like we were unable to do anything meaningful to help patients when we did everything right $(K R)$. On another occasion, we followed our ancestor's saying ' $Đ$ ồng tiền đi trước là đồng tiền khôn' (money paid in advance is wise money). It is not the 'right action' (KR, TEFNP) as we gave money to hospital officials but it worked and we could help patients $(K R)$. Sometimes, doing the 'right thing' does not always bring meaningful outcomes (KR) (B34V19)

At that time, we were willing to pay off officials to approve our project as we believed that our project to build a free vocational training center for the local community will be helpful $(K R)$ for those who were struggling to find a job [...] it is also a way for us to invest in future skilled labour for our company. However, part of our 'compromise' (KR) was to hand back the center for the local authorities to manage [...] we found that local officials received bribes to accept locals into the center, which was not our initial intent (impermanence) [...] we compromised ignorantly and our good intentions turned out to be meaningless [...] we need to be more skillful to deal with impermanence (SM, impermanence) $[\ldots]$ (B4V2)

Meaningful moments are found in failures and we all learn from failures to become better $(P T)$. It is important to have such moments to know your limits and shortcoming. Buddhist practice is all about personal transformation and failures are meaningful ingredients $(P T)[\ldots]$ you cannot play safe to fit in and expect to gain wisdom. Wisdom comes from lessons and failure (B24V14)

Meaningfulness for me comes from my failed experiences. The more I failed, the more knowledge I gained about myself and the world, and the more I understood and applied Buddhist practices more wisely (PT). (B10V5)

[...] It is not about finding my own version of meaningfulness or finding meaningfulness through others' but about freeing myself from all attachments (non-attachment), being free from personal desires and others' expectations. (B11V6) [...] Quitting the job which I personally find meaningless of unethical and get a new one is not the solution since I can neither control my new boss or colleagues nor can I can control the new working culture/norm at the new company (impermanence). Skillfully adapting and learning to let go of expectations and desires is the solution to abandon suffering (SM, non-attachment, TFNT). (B26V16)

I learnt to accept that there are always different opinions about what is right and what is wrong and I respect that (nonattachment). I adapt to certain viewpoints/decisions when the context supports them but raise my voice when they are no longer fit the context $(S M)$. I learnt to let go of fulfilling expectations or the fear of being judged (non-attachment). Being able to let go (non-attachment) is meaningfulness. (B8V4) 


\section{Quaker ethics influencing normative accounts of meaningful work}

Eternal and omnipresent

God is eternal, and we are all tasked with finding that which is eternal in everything we do. I Eternal try to find the meaning in the work I do and try to understand how that work contributes to building a better world (Q28U20)

So for me the purpose of work is how I find meaning. It doesn't matter what the job is, or what it looks like, or how much the salary is, so long as you are contributing to battling injustice in a small way. The job could be anything, but the purpose can't. (Q33U23)

Look, I am an administrator. And, many of friends think my job must be boring, mundane. Perhaps it is. If I looked at it as a set of tasks, yes it is. But, I know that my job reduces social disadvantage, offering opportunities to those who have no hope, I see a reflection of God in that moment (Q32U22)

Meaning is everywhere, all the time. Even the most mundane work can have spiritual meaning. Working in an industrial estate or a poor neighborhood can have meaning. It is your mindset that matters, and whether you can find God in small things, unusual things (Q1U1)

Moral accounts

While any work can be potentially meaningful, the benefits from work should not be solely individual and personal. Work must have a social purpose that reflects building a fairer and more equitable world (Q2U17)

Meaning at work can never be fully realized if it centers upon self and ego. More money, more power or privilege are likely to erode meaning in the long-run. The key for me is to know that I am making a difference to others, to those experiencing structural disadvantage or those in need (Q13U7)

I find meaning not for myself but for others that suffer injustice and disadvantage. This means I need to supress my ego and respond to God in an another (Q9U6)

The testimony to equality is key to living out Quakerism. Work can only be meaningful when you are dismantling these...[social]...inequalities (Q16U10)

We all need to live simply. This means, for me, a simple job without the entanglements of worrying about pay, power, privilege (Q6U4)

By fusing my professional and spiritual life, I now work entirely from a perspective of wholeness and service in life. I work with mindfulness and compassion. I emphasize integrity and values- led behavior, I question taken-for-granted practices, and have a real concern for equality and everyone having a voice. The Quaker testimonies are my guide (Q6U4)

Quaker values strongly influence my approach to my work life. I see myself as leading the organization towards positive change. The Quaker testimonies guide me in this endeavor (Q13U7)

Quakerism guides my choice of employment. I currently work fora charity and have scope to live out my values at work by working in service of others with less power and privilege (Q11U6)

It is quite straightforward, meaningful work is any work that furthers the development of God's kingdom for all of God's people (Q24U16)

Gods morals are my morals [...] I can only find true meaning in work that fulfils God's purpose (Q2U2)

We Quakers say 'finding that of God in everyone'. For me this plays out at work. If I can find that of God in another, and respond with grace to that presence of God, then work, like everything else, has meaning for me (Q3U3) 


\section{Quaker ethics influencing normative accounts of meaningful work}

Eternal and omnipresent

\section{Quotations}

Moral dilemmas in interpretations of meaningful work

I guess a key pinch point I experience is letting go of selfish desires and ego. I often find myself thoughtlessly chasing promotion, more pay, and things like that when I know I should be prioritizing the difference I can make in the world (Q34U23)

I remember leaving a senior position in a FTSE100 company. The car went back, the parking space, the laptop, the phone, all the paraphernalia that comes with a senior job. It was weird. I sort of felt naked for a few hours. I was no longer Head of... and was about to take up a much-lower paid role in a small charity doing work with disadvantaged communities. It takes so getting used to - the loss of all that status - but the new role brings so much joy making a difference to those facing social disadvantage. I often think back to my old 'self' and the power and privilege I had and sometimes don't even recognize him. Mind you, I miss the company car! (Q19U12)

A few years ago I applied for a new job and was verbally offered the role. I felt hugely uncomfortable, as a white man, being offered a senior role by white men. I questioned the diversity of the team and was told that they would 'be in touch'. They never did. While I am proud of my actions, I still struggle that this cost me dearly and I have my family and our comfort to think about too. Was it the right decision? I don't know (Q27U19)

I've been through a phase where I thought higher pay, nicer car, would kind of create meaning for me. But, more power often comes attached with tasks which are morally unacceptable. I had to make people redundant, impose pay freezes and so on as the quid pro quo of power. (Q21U13)

Often, work-places ask you to do things which are really challenging. Such as make someone redundant, or as simple as put the organization before your family. This is extremely challenging, and I've reached the conclusion that compromise is never worth it in the long run. I know that if I felt my desk would be occupied by a new recruit within days, there is never any real loyalty (Q15U9)

\section{Quaker-enacted responses to moral dilemmas}

\section{Resistance and moral disengagement_exiting}

My Quaker values inform my attitudes to work-I moved jobs to transform my outlook. I cannot any longer accept poor ethical practice. I resigned over the poor treatment of others (Q33U23)

I have worked with many great people, worked in great teams, but I remained empty and unfulfilled. It was all meaningless. To find purpose, I had to switch career to do work that tackled social disadvantage, injustice and inequality (Q25U17)

Of course, there is some degree of pragmatism required, I still need to support my family and pay the bills (Q8U5)

Leaving my job was the only way to reconcile my Quakerism with my professional life. You know, when you are continually asked to do tasks that you find morally concerning, you can only do it for so long. Quakers say, 'wear thy sword as long as you can', meaning metaphorically disarm yourself as soon as your conscious allows. Leaving my job was disarming myself of the emptiness that comes with working for a profit-seeking organization (Q27U19)

\section{Moral disengagement}

To me my Quakerism is central to my moral identity. I can sometimes only uphold this at work by dissenting and disengaging at work (Q22U14)

I have to find some meaning at work. My day job is tiresome, money, money, money. I have to put this aside. For example, I try to get some meaning by volunteering for the occasional good things my employer does. Last month, I participated in a sleep out to raise money for the homeless. That was satisfying (Q11UK6)

My work gives me no meaning. Unless I can carve out some time to do the work I want to. Luckily, my boss recognizes this, and I can spend a few days each month working at a charity that works with disadvantaged groups (Q32U22)

At work I am often faced with tasks that I find clash with my Quakerism. I do all I can to avoid them. It's a difficult ethical choice, but I try to spend more time doing things that are worthwhile, or at least neutral, and avoid the things I find ethically troubling. Dissenting and voicing concern is my strategy (Q4U3)

I try to spend my time at work on things that nurture my soul and the community. I volunteer, I get involved in community work, in outreach, and other things that support my Quaker faith. I do as little of my real job as I can get away with (Q19U12)
Quaker principles/practices

Building a fairer world

Social and moral purpose

Letting go of egoism

Quaker testimonies

Quaker theology—wear thy sword'

Fusing professional and personal moral values Social and moral purpose 


\section{Declarations}

Conflict of interest The authors declare that they have no conflict of interest.

Open Access This article is licensed under a Creative Commons Attribution 4.0 International License, which permits use, sharing, adaptation, distribution and reproduction in any medium or format, as long as you give appropriate credit to the original author(s) and the source, provide a link to the Creative Commons licence, and indicate if changes were made. The images or other third party material in this article are included in the article's Creative Commons licence, unless indicated otherwise in a credit line to the material. If material is not included in the article's Creative Commons licence and your intended use is not permitted by statutory regulation or exceeds the permitted use, you will need to obtain permission directly from the copyright holder. To view a copy of this licence, visit http://creativecommons.org/licenses/by/4.0/.

\section{References}

Adawiyah, W. R., \& Pramuka, B. A. (2017). Scaling the notion of Islamic spirituality in the workplace. Journal of Management Development, 36, 7877-7898.

Ahmad, A., \& Omar, Z. (2016). Workplace spirituality among Malaysian community service employees in the public sector. Asian Social Science, 12, 193-201.

Allan, B. A., Batz-Barbarich, C., Sterling, H. M., \& Tay, L. (2019). Outcomes of meaningful work: A meta-analysis. Journal of Management Studies, 56(3), 500-528.

Alshehri, F., Fotaki, M., \& Kauser, S. (2020). The effects of spirituality and religiosity on the ethical judgment in organizations. Journal of Business Ethics. https://doi.org/10.1007/s10551-020-04614-1

Bailey, C., Lips-Wiersma, M., Madden, A., Yeoman, R., Thompson, M., \& Chalofsky, N. (2019a). The five paradoxes of meaningful work: Introduction to the special issue 'meaningful work: Prospects for the 21st century.' Journal of Management Studies, 56(3), 481-499.

Bailey, C., \& Madden, A. (2016). What makes work meaningful-or meaningless? MIT Sloan Management Review, 57(4), 1-19.

Bailey, C., \& Madden, A. (2017). Time reclaimed: Temporality and the experience of meaningful work. Work, Employment and Society, 31(1), 3-18.

Bailey, C., Madden, A., Alfes, K., Shantz, A., \& Soane, E. (2017). The mismanaged soul: Existential labor and the erosion of meaningful work. Human Resource Management Review, 27(3), 416-430.

Bailey, C., Yeoman, R., Madden, A., Thompson, M., \& Kerridge, G. (2019b). A review of the empirical literature on meaningful work: Progress and research agenda. Human Resource Development Review, 18(1), 83-113.

Bandura, A. (1991). Social cognitive theory of moral thought and action. In W. M. Kurtines \& J. L. Gewirtz (Eds.), Handbook of moral behavior and development (pp. 45-103). Lawrence Erlbaum.

Bandura, A. (1999). Moral disengagement in the perpetration of inhumanities. Personality and Social Psychology Review, 3, 193-209.

Bandura, A. (2001). Social cognitive theory: An agentic perspective. Annual Review of Psychology, 52, 1-26.

Bandura, A. (2006). Toward a psychology of human agency. Perspectives on Psychological Science, 1(2), 164-180.

Bandura, A. (2011). Social cognitive theory. In P. A. M. Van Lange, A. W. Kruglanski, \& E. T. Higgins (Eds.), Handbook of theories of social psychology (pp. 349-373). Sage.
Bandura, A., Barbaranelli, C., Caprara, G. V., \& Pastorelli, C. (1996). Mechanism of moral disengagement in the exercise of moral agency. Journal of Personality and Social Psychology, 71(2), 364-374.

Baumeister, R. F., Vohs, K. D., Aaker, J. L., \& Garbinsky, E. N. (2013). Some key differences between a happy life and a meaningful life. The Journal of Positive Psychology, 8(6), 505-516.

Beadle, R., \& Knight, K. (2012). Virtue and meaningful work. Business Ethics Quarterly, 22, 433-450.

Bodhi, B. (1984). The noble eightfold path (p. 63). Buddhist Publication Society.

Both-Nwabuwe, J., Dijkstra, M. T. M., \& Beersma, B. (2017). How to define and measure meaningful work. Frontiers in Psychology. https://doi.org/10.3389/fpsyg.2017.01658

Brogaard, B. (2008). Moral contextualism and moral relativism. The Philosophical Quarterly, 58(232), 385-409.

Brooks, J., McCluskey, S., Turley, E., \& King, N. (2015). The utility of template analysis in qualitative psychology research. Qualitative Research in Psychology, 12(2), 202-222.

Buckley, M. (2013). A constructivist approach to business ethics. Journal of Business Ethics, 117(4), 695-706.

Bunderson, J. S., \& Thompson, J. A. (2009). The call of the wild: Zookeepers, callings, and the double-edged sword of deeply meaningful work. Administrative Science Quarterly, 54(1), 32-57.

Burton, N., \& Bainbridge, J. (2019). Spiritual discernment, the incorporated organization, and corporate law: The case of Quaker business method. Religions, 10(1), 35.

Burton, N., \& Galvin, P. (2018). Using template and matrix analysis: A case study of management and organisation history research. Qualitative Research in Organizations and Management, 14(4), 393-409.

Burton, N., Koning, J., \& Muers, R. (2018). Organizational ethnography and religious organizations: The case of Quaker decisionmaking. Journal of Management, Spirituality \& Religion, 15(4), 349-367.

Burton, N., \& Sinnicks, M. (2021). Quaker business ethics as MacIntyrean tradition. Journal of Business Ethics. https://doi.org/10. 1007/s10551-020-04706-y

Burton, N., \& Vu, M. C. (2020). Moral identity and the Quaker tradition: Moral dissonance negotiation in the workplace. Journal of Business Ethics. https://doi.org/10.1007/s10551-020-04531-3

Burton, N., \& Vu, M. C. (2021). The light and the dark of mindful social capital: Right mindfulness and social capital development. European Management Review, 18(1) 137-150. https://doi.org/ 10.1111/emre.12427

Busse, R., Kwon, S., Kloep, H. A., Ghosh, K., \& Warner, M. (2018). Toward a "meaningful self" at the workplace: Multinational evidence from Asia, Europe, and North America. Journal of Leadership \& Organizational Studies, 25(1), 63-75.

Carton, A. M. (2018). "I'm not mopping the floors, I'm putting a man on the moon": How NASA leaders enhanced the meaningfulness of work by changing the meaning of work. Administrative Science Quarterly, 63(2), 323-369.

Cartwright, S., \& Holmes, N. (2006). The meaning of work: The challenge of regaining employee engagement and reducing cynicism. Human Resource Management Review, 16(2), 199-208.

Cavanagh, G. F., \& Bandsuch, M. R. (2002). Virtue as a benchmark for spirituality in business. Journal of Business Ethics, 38(1-2), 109-117.

Chu, I., \& Vu, M. C. (2021). The nature of the self, self-regulation and moral action: Implications from the confucian relational self and Buddhist non-self. Journal of Business Ethics, 1-18.

Ciulla, J. (2000). The working life: The promise and betrayal of modern work. Three Rivers Press. 
Ciulla, J. B. (2012). Worthy work and Bowie's Kantian theory of meaningful work. In D. Arnold \& J. Harris (Eds.), Kantian business ethics (pp. 115-131). Edward Elgar.

Collins, P., \& Dandelion, P. (2014). Transition as normative: British Quakerism as liquid religion. Journal of Contemporary Religion, 29(2), 287-301.

Cooper, D. E., \& James, S. P. (2005). Buddhism, virtue and environment. Ashgate.

Dandelion, P. (2004). Research note. Implicit conservatism in liberal religion: British Quakers as an 'uncertain sect.' Journal of Contemporary Religion, 19(2), 219-229.

Dandelion, P. (2008). The Quakers: A very short introduction. Oxford University Press.

Dandelion, P. (2014). The British Quaker survey 2013. Quaker Religious Thought, 123(1), 15.

Dandelion, P. (2017). The liturgies of Quakerism. Taylor \& Francis.

Daniels, P. (2007). Buddhism and the transformation to sustainable economies. Society and Economy, 29(2), 155-180.

Florian, M., Costas, J., \& Kärreman, D. (2019). Struggling with meaningfulness when context shifts: Volunteer work in a German refugee shelter. Journal of Management Studies, 56(3), 589-616.

Fromm, E. (1990). The sane society. Holt, Rinehart \& Winston.

Gabriel, Y. (1999). Beyond happy families: A critical re-evaluation of the control-resistance-identity triangle. Human Relations, 52, 179-203.

Gallie, W. B. (1956). Essentially contested concepts. Proceedings of the Aristotelian Society, 56, 167-198.

Gampopa, S. (1998). The jewel ornament of liberation: the wish-fulfilling gem of the noble teachings. Snow Lion Publications.

Garfield, J. L., Nichols, S., Rai, A. K., \& Strohminger, N. (2015). Ego, egoism and the impact of religion on ethical experience: What a paradoxical consequence of Buddhist culture tells us about moral psychology. The Journal of Ethics, 19(3-4), 293-304.

Gombrich, R. (1996). How Buddhism began. Athlone Press.

Grant, A. M. (2007). Relational job design and the motivation to make a prosocial difference. Academy of Management Review, 32, 393-417.

Grant, A. M., Campbell, E. M., Chen, G., Cottone, K., Lapedis, D., \& Lee, K. (2007). Impact and the art of motivation maintenance: The effects of contact with beneficiaries on persistence behavior. Organizational Behavior and Human Decision Processes, 103, 53-67.

Harding, N. (2019). Identity and meaningful/less work. In R. Yeoman, C. Bailey, A. Madden, \& M. Thompson (Eds.), The Oxford handbook of meaningful work. Oxford University Press.

Harpaz, I., \& Fu, X. (2002). The structure of the meaning of work: A relative stability amidst change. Human Relations, 55, 639-667.

Harvey, P. (2012). An introduction to Buddhism: Teachings, history and practices. Cambridge University Press.

Helminiak, D. A. (2011). Spirituality as an explanatory and normative science: Applying Lonergan's analysis of intentional consciousness to relate psychology and theology. The Heythrop Journal, 52(4), 596-627.

Hitlin, S., \& Elder, G. H., Jr. (2007). Time, self, and the curiously abstract concept of agency. Sociological Theory, 25(2), 170-191.

Huang, T. R., \& Wang, Y. H. (2019). Perceiving self, others, and events through a religious lens: Mahayana Buddhists vs. Christians. Frontiers in Psychology, 10, 217.

Isaksen, J. (2000). Constructing meaning despite the drudgery of repetitive work. Journal of Humanistic Psychology, 40(3), 84-107.

Johansen, B. C. P., \& Gopalakrishna, D. (2006). A Buddhist view of adult learning in the workplace. Advances in Developing Human Resources, 8(3), 337-345.

Jones, T. M. (1991). Ethical decision making by individuals in organisations: An issue-contingent model. Academy of Management Review, 16(2), 366-395.
Kang, J. H., Matusik, J. G., \& Barclay, L. A. (2017). Affective and normative motives to work overtime in Asian organizations: Four cultural orientations from Confucian ethics. Journal of Business Ethics, 140(1), 115-130.

Kelley, P. C., \& Elm, D. R. (2003). The effect of context on moral intensity of ethical issues: Revising Jones's issue-contingent model. Journal of Business Ethics, 48(2), 139-154.

Kern, H. (1989). Manual of Indian Buddhism. Motilal Banarsidass Publications.

King, N. (1998). Template analysis. In G. Symon \& C. Cassell (Eds.), Qualitative methods and analysis in organisational research (pp. 118-134). Sage.

King, N. (2004). Using templates in the thematic analysis of texts. In G. Symon \& C. Cassell (Eds.), Qualitative methods and analysis in organisational research (pp. 256-270). Sage.

Kobasa, S. C., \& Puccetti, M. C. (1983). Personality and social resources in stress resistance. Journal of Personality and Social Psychology, 45(4), 839.

Lama, D. (1995). The power of compassion. Thorsons.

Lazarus, R. S., \& Folkman, S. (1984). Stress, appraisal, and coping. Springer.

Lepisto, D. A., \& Pratt, M. G. (2017). Meaningful work as realization and justification: Toward a dual conceptualization. Organizational Psychology Review, 7(2), 99-121.

Lindtner, C. (1986). Master of wisdom: Writings of the Buddhist master Nāgārjuna. Dharma Publication.

Lips-Wiersma, M. (2002). The influence of "spiritual meaning-making" on career behavior. The Journal of Management Development, 21, 497-520.

Lips-Wiersma, M., Haar, J., \& Wright, S. (2020). The effect of fairness, responsible leadership and worthy work on multiple dimensions of meaningful work. Journal of Business Ethics, 161, 35-52.

Lips-Wiersma, M., \& Morris, L. (2009). Discriminating between 'meaningful work' and the 'management of meaning.' Journal of Business Ethics, 88(3), 491-511.

Lysova, E. I., Allan, B. A., Dik, B. J., Duffy, R. D., \& Steger, M. F. (2019). Fostering meaningful work in organizations: A multilevel review and integration. Journal of Vocational Behavior, 110, 374-389.

Macey, W. H., \& Schneider, B. (2008). The meaning of employee engagement. Industrial and Organizational Psychology, 1(1), 3-30.

MacIntyre, A. (1999). Social structures and their threats to moral agency. Philosophy, 74(3), 311-329.

MacIntyre, A. (2008). What more needs to be said? A beginning, although only a beginning, at saying it. Analyse \& Kritik, 30(1), 261-281.

Madill, A., Jordan, A., \& Shirley, C. (2000). Objectivity and reliability in qualitative analysis: Realist, contextualist and radical constructionist epistemologies. British Journal of Psychology, 91(1), 1-20.

Marques, J. (2010). Toward greater consciousness in the 21 st century workplace: How Buddhist practices fit in. Journal of Business Ethics, 92, 211-225.

May, D. R., Gilson, R. L., \& Harter, L. M. (2004). The psychological conditions of meaningful- ness, safety and availability and the engagement of the human spirit at work. Journal of Occupational and Organizational Psychology, 77, 11-37.

May, D. R., Li, C., Mencl, J., \& Huang, C.-C. (2014). The ethics of meaningful work: Types and magnitude of job-related harm and the ethical decision-making process. Journal of Business Ethics, $121,651-669$.

Michaelson, C. (2009). Meaningful work and moral worth. Business and Professional Ethics Journal, 28(1/4), 27-48.

Michaelson, C. (2019). A normative meaning of meaningful work. Journal of Business Ethics, 170, 1-16. 
Michaelson, C., Pratt, M. G., Grant, A. M., \& Dunn, C. P. (2014). Meaningful work: Connecting business ethics and organization studies. Journal of Business Ethics, 121(1), 77-90.

Mitra, R., \& Buzzanell, P. M. (2017). Communicative tensions of meaningful work: The case of sustainability practitioners. Human Relations, 70(5), 594-616.

Moore, G., \& Beadle, R. (2006). In search of organizational virtue in business: Agents, goods, practices, institutions and environments. Organization Studies, 27(3), 369-389.

Muers, R. (2015). Testimony: Quakerism and theological ethics. SCM Press.

Muers, R., \& Burton, N. (2019). Can we take the religion out of religious decision-making? The case of Quaker business method. Philosophy of Management, 18(3), 363-374.

Newman, A., Le, H., North-Samardzic, A., \& Cohen, M. (2020). Moral disengagement at work: A review and research agenda. Journal of Business Ethics, 1167, 535-570.

Nussbaum, M. C. (1997). Capabilities and human rights. Fordham Law Review, 66, 273-300.

Organ, T. W. (1954). The silence of the Buddha. Philosophy East and West, 4(2), 125-140.

Pardasani, R., Sharma, R. R., \& Bindlish, P. (2014). Facilitating workplace spirituality: Lessons from Indian spiritual traditions. Journal of Management Development, 33, 847-859.

Pew Research Center (2020). Vietnam: Religious demography: Affiliation. Retrieved March 3, 2021, from http://www.globalreligious futures.org/countries/vietnam\#/?affiliations_religion_id=0\&affil iations_year $=2020 \&$ region_name $=A 11 \% 20$ Countries\&restrictio ns_year $=2016$

Purser, R. E., \& Milillo, J. (2015). Mindfulness revisited: A Buddhistbased conceptualization. Journal of Management Inquiry, 24(1), $3-24$.

Rajavaramuni, P. (1990). Introduction. In F. S. Russell \& K. S. Donald (Eds.), Ethics, wealth, and salvation: A study in Buddhist social ethics. University of South Carolina Press.

Ray, R. A. (2002). Secret of the vajra world: The tantric Buddhism of Tibet. Shambhala Publications.

Reinecke, J., van Bommel, K., \& Spicer, A. (2017). When orders of worth clash: Negotiating legitimacy in situations of moral multiplexity. Research in the Sociology of Organizations, 52, 33-72.

Renard, M., \& Snelgar, R. J. (2016). How can work be designed to be intrinsically reward-ing? Qualitative insights South African nonprofit employees. SA Journal of Industrial Psychology, 42, 1-12.

Rhys-Davids, T. W. (1899). Dialogues of the Buddha: Sacred books of the Buddhists (Vol. II). Oxford University Press.

Rinpoche, S. (1992). The Tibetan book of living and dying. HarperColllins.

Robson, A. (2015). Constancy and integrity:(un) measurable virtues? Business Ethics, 24, S115-S129.

Rosso, B. D., Dekas, K. H., \& Wrzesniewski, A. (2010). On the meaning of work: A theoretical integration and review. Research in Organizational Behavior, 30, 91-127.

Schroeder, J. W. (2004). Skillful means: The heart of Buddhist compassion (Vol. 54). Motilal Banarsidass Publication.

Schroeder, J. (2011). Truth, deception, and skillful means in the Lotus Sūtra. Asian Philosophy, 21(1), 35-52.

Scott, W. R. (1995). Institutions and organizations. Sage.

Scully, J. L. (2010). Virtuous friends: Morality and Quaker identity. Quaker Studies, 14(1), 6.

Seachris, J. W. (Ed.). (2013). General introduction to exploring the meaning of life: An anthology and guide. Wiley-Blackwell.

Selznick, P. (1948). Foundations of the theory of organization. American sociological review, 13(1), 25-35.

Sen, A. (1985). Commodity and capabilities. North Holland.
Sheep, M. L. (2006). Nurturing the whole person: The ethics of workplace spirituality in a society of organizations. Journal of Business Ethics, 66(4), 357-375.

Shin, H., Vu, M. C., \& Burton, N. (2021). Micro-processes of moral normative engagement with CSR tensions: The role of spirituality in justification work. Journal of Business Ethics, 1-19.

Sinnicks, M. (2018). Leadership after virtue: MacIntyre's critique of management reconsidered. Journal of Business Ethics, 147(4), 735-746.

Steger, M. F., Littmann-Ovadia, H., Miller, M., Menger, L., \& Rothmann, S. (2013). Engaging in work even when its meaningless: Positive affective disposition and meaningful work interact in relation to work engagement. Journal of Career Assessment, 21, 348-361.

Stein, M. K., Wagner, E. L., Tierney, P., Newell, S., \& Galliers, R. D. (2019). Datification and the pursuit of meaningfulness in work Journal of Management Studies, 56(3), 685-717.

Tablan, F. (2019). Virtue ethics and meaningful work: A contemporary Buddhist approach. Humanities Bulletin, 2(2), 22-38.

Thich, N. H. (1999). The heart of the Buddha's teaching: Transforming suffering into peace, joy and liberation. Broadway Books.

Toraldo, M. L., Islam, G., \& Mangia, G. (2019). Serving time: Volunteer work, liminality and the uses of meaningfulness at music festivals. Journal of Management Studies, 56(3), 617-654.

Tourish, D. (2019). Leadership and meaningful work. In R. Yeoman, C. Bailey, A. Madden, \& M. Thompson (Eds.), The Oxford handbook of meaningful work. Oxford University Press.

Tsong-Kha-pa, J. (2004). The great treatise on the stages of the path to enlightenment (Vol. 1). Snow Lion Publications.

$\mathrm{Vu}, \mathrm{M}$. C. (2020). How the contextual constraints and tensions of a transitional context influence individuals' negotiations of meaningful work-the case of Vietnam. The International Journal of Human Resource Management. https://doi.org/10.1080/09585 192.2020.1745867

Vu, M. C. (2021). Tensions and struggles in tackling bribery at the firm level: Perspectives from Buddhist-enacted organizational leaders. Journal of Business Ethics, 168, 517-537.

Vu, M. C., \& Burton, N. (2020). Mindful reflexivity: Unpacking the process of transformative learning in mindfulness and discernment. Management Learning, 51(2), 207-226.

Vu, M. C., \& Tran, T. (2021). Trust Issues and engaged Buddhism: The triggers for skillful managerial approaches. Journal of Business Ethics, 169, 77-102.

Walvin, J. (1997). The Quakers: Money and morals. John Murray.

Wang, Z., \& Xu, H. (2019). When and for whom ethical leadership is more effecting in eliciting work meaningfulness and positive attitudes: The moderating roles of core self-evaluation and perceived organizational support. Journal of Business Ethics, 156(4), 919-940.

Watson, B. (1993). The Zen teachings of master Lin-chi. Shambhala Publications.

Williams, P. (1989). Mahayana Buddhism: The doctrinal foundations. Routledge.

Wolf, S. (2010). Meaning in life and why it matters. Princeton University Press.

Yeoman, R. (2014). Conceptualising meaningful work as a fundamental human need. Journal of Business Ethics, 125(2), 235-251.

Zhang, S. (2020). Workplace spirituality and unethical pro-organizational behavior: The mediating effect of job satisfaction. Journal of Business Ethics, 161(3), 687-705.

Publisher's Note Springer Nature remains neutral with regard to jurisdictional claims in published maps and institutional affiliations. 